\title{
NEUROPSYCHOPHARMACOLOGY REVIEWS Sex differences in neural mechanisms mediating reward and addiction
}

\author{
Jill B. Becker ${ }^{1}$ and Elena Chartoff ${ }^{2}$
}

\begin{abstract}
There is increasing evidence in humans and laboratory animals for biologically based sex differences in every phase of drug addiction: acute reinforcing effects, transition from occasional to compulsive use, withdrawal-associated negative affective states, craving, and relapse. There is also evidence that many qualitative aspects of the addiction phases do not differ significantly between males and females, but one sex may be more likely to exhibit a trait than the other, resulting in population differences. The conceptual framework of this review is to focus on hormonal, chromosomal, and epigenetic organizational and contingent, sexdependent mechanisms of four neural systems that are known_primarily in males— to be key players in addiction: dopamine, muopioid receptors (MOR), kappa opioid receptors (KOR), and brain-derived neurotrophic factor (BDNF). We highlight data demonstrating sex differences in development, expression, and function of these neural systems as they relate-directly or indirectly - to processes of reward and addictive behavior, with a focus on psychostimulants and opioids. We identify gaps in knowledge about how these neural systems interact with sex to influence addictive behavior, emphasizing throughout that the impact of sex can be highly nuanced and male/female data should be reported regardless of the outcome.
\end{abstract}

Neuropsychopharmacology (2019) 44:166-183; https://doi.org/10.1038/s41386-018-0125-6

\section{INTRODUCTION}

The addiction landscape in 2018

Only a small percentage of men and women who sample psychoactive drugs of any kind will develop an addictive disorder $[1,2]$. The most recent data we have for use of illicit drugs by sex/ gender in the USA is from the 2013 National Survey on Drug Use and Health published by SAMHSA [3]. The data are relatively consistent with those of previous years, in that for ages 18 and older, a greater percentage of men than women are dependent or abusing illicit drugs. Interestingly, the percentage of women has been constant since 2010 at 5.8 percent, while the percentage of men has declined slightly. This same trend is also seen in tobacco use (ibid). In this review we will be focusing primarily on sex differences in the behavioral effects of, and the molecular mechanisms of, psychostimulants (e.g., cocaine, methamphetamine, and amphetamine) and opioids (e.g., morphine, oxycodone, and heroin).

There are no sex/gender differences in the percentages of youth between the ages of 12-25 dependent on, or abusing, illicit drugs, which has been true since 2002. However, there have been sex/gender differences in abuse and dependence on individual drugs across the years [4]. For example, males (ages 12-25) are more likely to abuse or be dependent upon marijuana or alcohol, whereas similar aged females are more likely to abuse or be dependent upon cocaine and psychotherapeutic drugs [4]. In a recent cross-cultural analysis of sex/gender differences in substance use disorders, McHugh et al [5] concluded, "Although there is significant variation across cultures, in general, men are more likely to have access to substances relative to women; this difference in access appears to account for much of the gender difference in the prevalence of substance use. In other words, when controlling for access, the likelihood of substance use does not differ between men and women" [5]. Thus, sex differences in the absolute number of individuals using drugs is not key to understanding sex differences in addictive disorders. Rather. sex differences in the patterns of drug use and in the paths to addiction for individual drugs are more likely to provide information useful for treatment and prevention.

There has been recent attention on the extensive abuse of prescription opioid drugs and heroin by women and the subsequent increase in deaths of women due to opioid overdose. A recent review of sex/gender differences in prescription opioid medications and heroin use in the USA, from 2007 to 2014, found that the number of women using heroin is increasing at a faster rate than for men, even though non-medical prescription opioid drug use is declining for both sexes [6]. While some studies have found females at greater risk for opioid overdose, a recent meta-analysis suggests that the risk factors associated with overdose are complicated and not necessarily related to greater female risk $[7,8]$.

There are however, sex/gender differences in the reasons for initiating drug use and the path from initial drug use to being diagnosed with a substance use disorder. The best available data are for alcohol, but similar patterns are seen for other drugs of abuse. Self-reports indicate that many adolescent girls and women initiate drug use as a coping strategy to deal with anxiety, low self-esteem, depression, and feelings of isolation $[9,10]$. These negative affective states are reported more frequently in women compared to men [11]. Prior sexual abuse and violence are more frequently reported by women than men with substance use disorders, including opioid use disorder, and this type of trauma is more predictive of substance

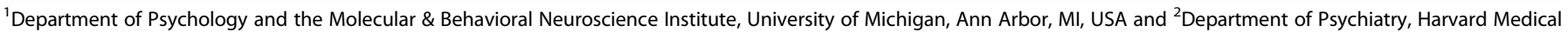
School, McLean Hospital, Belmont, MA, USA

Correspondence: Elena Chartoff (echartoff@mclean.harvard.edu)

Received: 12 March 2018 Revised: 27 April 2018 Accepted: 11 June 2018

Published online: 19 June 2018 
use disorder in women $[12,13]$, highlighting the difficulty in parsing out effects of biology from societal norms. While some men also self-medicate with drugs of abuse, most report initiating drug use to be "part of the group" by demonstrating their willingness to engage in risky behaviors $[11,14]$.

Thus, in 2018 we are facing an addiction landscape characterized by decreasing sex/gender differences in the prevalence of drug taking behaviors and substance use disorder. Rather, the landscape is revealing sex/gender differences in the initiation, escalation, and withdrawal effects of drug taking behaviors. These sex/gender differences are compounded by the effects of sexual abuse and trauma, which tend to increase rates of substance use disorder in women to a greater extent than in men. Thus, to understand sex/gender differences in substance use disorder we need to better understand the neural mechanisms mediating addictive behavior in both sexes, and how developmental events impact the neural circuitry in both sexes. In the following sections we primarily review preclinical research conducted in laboratory models of addiction, which provide remarkable predictive, face, and construct validity to the human condition of substance use disorder.

Neural systems mediating reward, motivation, and addiction Stages of addiction and overview of sex differences therein. The transition from casual drug use to substance use disorder in humans is influenced by a confluence of innate traits such as biological sex, impulsivity, sensitivity, anxiety, risk-taking behavior, and social and environmental influences such as socioeconomic status, education, exposure to trauma and abuse, peer pressure, drug availability, family drug use, and the social construct of gender. Despite these complexities, studies have identified neural circuits and molecular players involved in the development and maintenance of addiction. The development of addiction can be described as a three-stage cycle: 1. initiation/escalation, 2. withdrawal/negative affect, and 3. preoccupation/craving [15]. A key stage of the addiction cycle is the transition from initiation to escalation to compulsive drug use $[16,17]$. One facet of this transition is the switch from drug taking as a goal-directed behavior to a compulsive behavior, which is thought to involve a shift from ventral corticostriatal circuitry involving prefrontal cortex and ventromedial striatum, to a more dorsal circuit involving the dorsolateral striatum [18]. Below we provide a brief synopsis of the major neural circuits implicated in these stages of addiction, with a focus on opioids (mu-opioid receptor (MOR) agonists such as morphine, heroin, and oxycodone) and psychostimulants (e.g., cocaine, amphetamines). Comprehensive reviews are recommended for more in-depth coverage [15, 19-23].

Clinical data support the idea that women who develop substance use disorders escalate from initial drug use to compulsive drug-taking more rapidly than men, a phenomenon known as "telescoping" [14, 24, 25]. Women also report more negative affect during withdrawal than men and have greater stress- and cue-induced craving and relapse compared with men (reviewed in [26]). Sex differences are also seen in rodent models of the different phases of addiction [26-28], highlighting the importance of in-depth studies in laboratory animals that can identify underlying neurobiological mechanisms. Although little research has been published on gender differences in heroin use patterns in humans, research in rodent models of addiction have shown that females acquire heroin self-administration more rapidly than males and show greater motivation to take heroin compared to males [26]. Interestingly, the same has not been found for the prescription opioid oxycodone: naive males and females acquire oxycodone self-administration behavior at similar rates, but males take significantly more drug than females during the initial acquisition sessions [29]. Whether these differences in male versus female rodent behavior are due to sex differences in the pharmacological responses to heroin and oxycodone or to differences in experimental design are not known. A take-home message from these types of disparate data is that although it is tempting to try to fit preclinical behavioral data on addiction-like behavior to substance use disorder in women, the preclinical findings do not always match the human condition. Rather than conclude that these preclinical studies of addiction are pointless, we argue that it is imperative for researchers to report the data from animal studies-regardless if they match the clinical condition-and then leverage the power of animal models to probe underlying mechanisms.

Initiation/escalation: The mesocorticolimbic dopamine pathway, comprising the ventral tegmental area, nucleus accumbens, and prefrontal cortex is consistently identified as a common neural substrate of all drugs of abuse [23, 30, 31]. Psychostimulants such as cocaine and amphetamine block monoamine reuptake transporters at nerve terminals to directly increase levels of dopamine and other monoamines, whereas opioids act on MORs in the ventral tegmental area to decrease the activity of inhibitory $\gamma$-aminobutyric acid (GABA) interneurons, which results in a greater release of dopamine in forebrain regions [32, 33]. The last several decades of research have identified multiple roles for dopamine: it stamps in salience to stimuli in the environment, and it promotes behavioral activation and performance of goaldirected behavior [34, 35]. The time course of dopamine signaling is also a key factor. Rapid, phasic dopamine cell firing tends to code the experience of reward and determine the value of predicted outcomes of behavior, whereas tonic dopamine cell firing results in lower amounts of dopamine release that can facilitate and enable reward-related neural systems associated with motivational drive [36].

Dopamine neurons in the ventral tegmental area project to forebrain regions including the nucleus accumbens, prefrontal cortex, and amygdala (Fig. 3). The nucleus accumbens receives information related to hedonic state from dopamine and from neuromodulators such as brain-derived neurotrophic factor (BDNF), neuropeptides such as dynorphin (DYN), and from excitatory glutamaterigic afferents originating in the amygdala, frontal cortex, hippocampus, and thalamus [37-39]. The nucleus accumbens integrates this information and converts it to motivational action via connections with the extrapyramidal motor system.

Withdrawal/negative affective states: Repeated exposure to the acute rewarding effects of drugs can lead to escalation of drug intake [40], which causes a homeostatic impairment of the mesolimbic dopamine system. These homeostatic changes, described broadly as "opponent processes", can occur directly within dopamine signaling pathways or indirectly within neuromodulatory systems that regulate dopamine signaling. Both mechanisms are thought to contribute to negative affective states observed during periods of drug withdrawal and abstinence. The homeostatic adaptations that occur in response to chronic drug exposure serve to oppose reward and, paradoxically, reinforce drug-seeking behavior [22, 41, 42].

One type of opponent process to chronic drug administration is engagement of extra-hypothalamic stress systems including increased activity of corticotropin-releasing factor (CRF) and DYN within the extended amygdala [38, 41]. The extended amygdala, which is composed of the central nucleus of the amygdala, bed nucleus of the stria terminalis, and a medial portion of the nucleus accumbens shell, represents a common anatomical substrate that integrates stress and reward systems to produce drug withdrawalinduced negative affective states and promote negative reinforcement processes associated with the development of addiction.

Preoccupation/craving/relapse: Craving is difficult to study in animal models as it is a highly subjective, emotion-based state. 


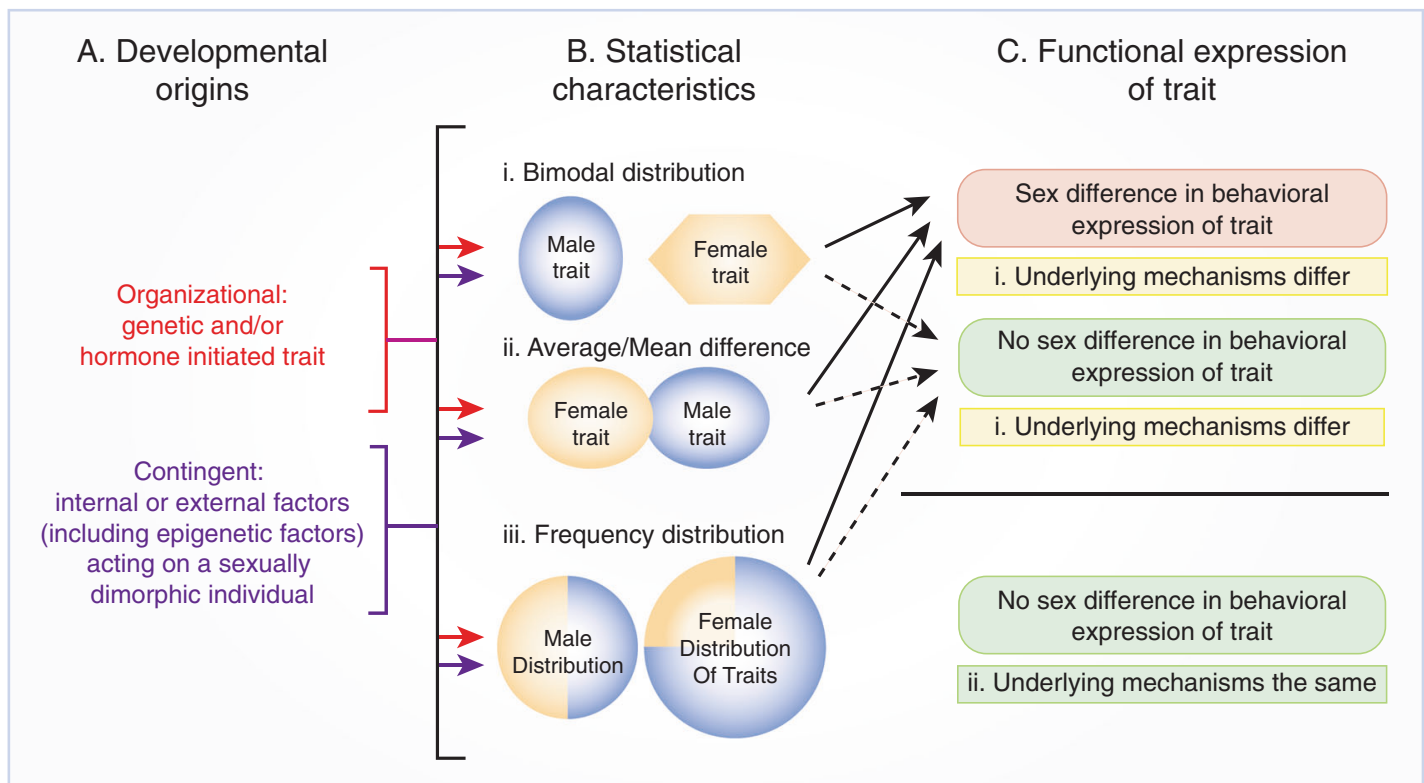

Fig. 1 Developmental origins, statistical characteristics, and functional expression of sex differences in the brain. a Developmental origins of sex differences may arise from organizational influences or be contingent on interaction with internal or external factors. Organizational origins are defined as genetic (XY /XX chromosomes), gonadal hormone influences during critical/sensitive periods of development, and placental influences. Contingent origins include internal or external factors that include epigenetic traits induced by environmental exposure, effects of stress in utero or postnatal, nutritional factors, etc. b Statistical Characteristics that describe different types of sex differences. These occur due to multiple developmental processes. Sex differences may exist in four forms, three of which involve differences in behavioral output: i. Bimodal Distribution; ii. Average or Mean differences; iii. Frequency Distribution differences in trait occurrence. The fourth form of sex difference occurs when behavioral expression of a trait is statistically similar between males and females, but the underlying mechanisms are significantly different. c Functional Expression of Trait. Traits may be expressed differently in females and males, or the sexes may show similar expression of the trait (by the measures used) but get to the trait by different underlying mechanisms (i) or via the same mechanism (ii)

Recent advances in neuroimaging techniques and ecological momentary assessment approaches to studying craving and drug use episodes in real time in individuals with substance use disorders have shown that drug-cue and stress-induced craving for cocaine and opiates activates regions of the prefrontal cortex, amygdala, hippocampus, insula, and the ventral tegmental area [43]. In human studies, cocaine-dependent females show greater reactivity in these brain regions to stress and drug cues during drug craving whereas cocaine-dependent males show greater responses to drug cues [44].

The phenomenon of relapse is well modeled in laboratory animals using the reinstatement procedure [45]. Evidence from animal studies suggests that neural circuit changes associated with drug-induced and cue-induced reinstatement after extinction of operant responding for drug are linked to glutamatergic projections from the prefrontal cortex to the nucleus accumbens core, dopamine projections from the ventral tegmental area to the medial prefrontal cortex, and GABA projections from the nucleus accumbens to the ventral pallidum. In contrast, stress-induced reinstatement of drug seeking depends more on activation of DYN, CRF, and norepinephrine systems within the extended amygdala [46-48].

Origins of sex differences mediating reward, motivation, and addiction

Overview of sex differences. Historically our language forces us into a bimodal view of the sexes (i.e., males and females are "opposite sexes"), which has made it difficult to accept that complex interactions between biological characteristics and environmental factors contribute to the ultimate expression of traits that fall on a continuum ranging from "opposite" to "identical". There have been a number of recent reviews that have described these interactions and the consequent expression of sex differences in brain and behavior [26, 49-52].
Considering the types of sex/gender differences is helpful when you have collected data and need to think about what it means for the neurobiological processes being investigated. Becker and Koob [26] described four types of sex/gender differences: (1) qualitative differences (traits are phenotypically different as typified by a bimodal distribution); (2) quantitative differences (sexes/genders exhibit different averages or means for a trait); (3) population differences (frequency differences in the number of individuals of each sex/gender that exhibits a particular trait) and; (4) mechanistic/convergent differences (the trait is the same for both sexes but the underlying biology differs).

Thinking conceptually about the neurobiological processes through which these four types of sex differences arise is helpful, as illustrated in Fig. 1. There are specific developmental influences that affect the expression of sex differences in the adult. The sex chromosomes, parent-of-origin inheritance of autosomal allele bias, fetal, and pubertal gonadal hormones and the placenta contribute to the sexspecific development of the brain [49, 50, 53, 54]. Applying this conceptual framework to the topic of addiction, there is evidence for each type of sex difference in the causes of, expression of, and consequences of addiction (see [26] for details on specific drugs).

The following sections are organized to first provide an overview of the types of processes (e.g., hormonal, genetic, and epigenetic) that contribute to sex differences in neurobiological mechanisms underlying addictive behavior. These processes underlie sex differences in every realm of brain and behavior and are not unique to addiction. However, it is necessary to understand the current state of knowledge on the origin of sex differences in order to understand how males and females differ (or do not differ) in the different phases of the addiction cycle. Second, this review then uses four key neural systems (dopamine, MOR, kappa opioid receptor (KOR), and BDNF) as examples of how these mechanisms have been shown to specifically impact addiction-like behavior in a sex-dependent manner. 


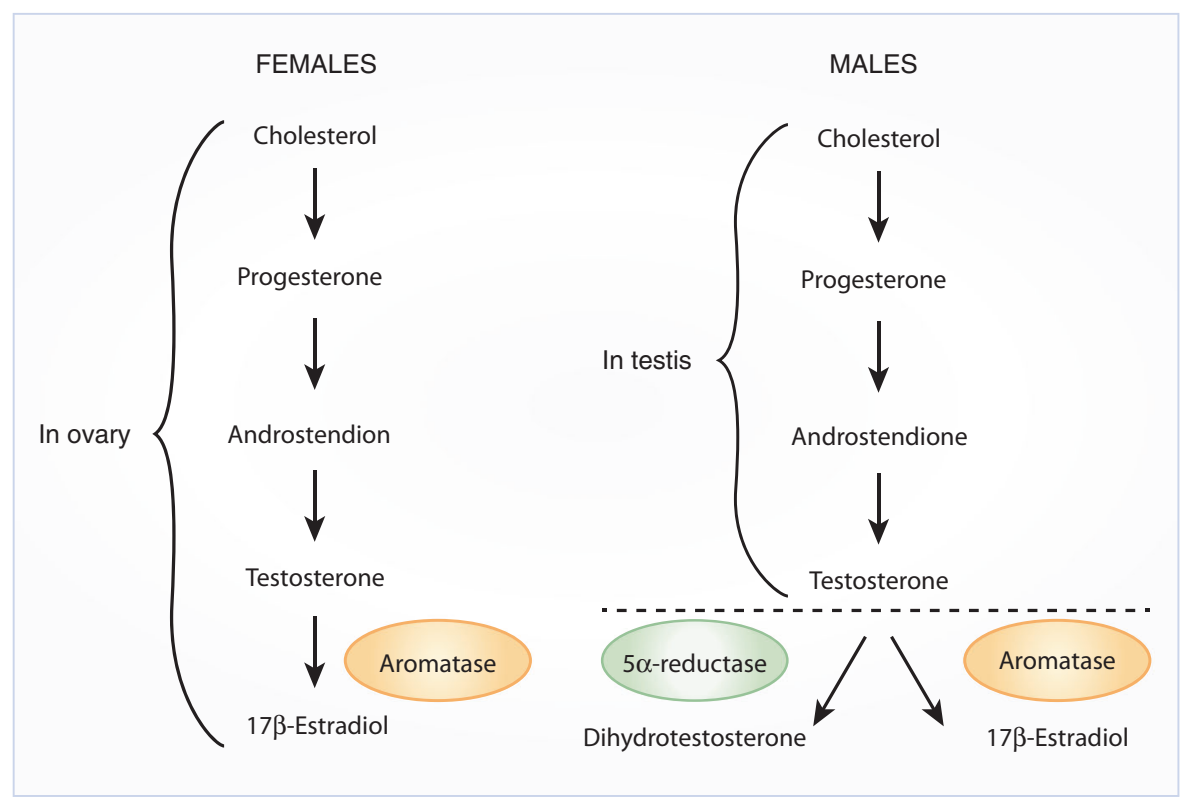

Fig. 2 Synthesis of gonadal hormones. The primary gonadal hormones: progesterone, testosterone and estradiol are part of the same synthetic pathway as described in this figure. In females all steps of the synthetic pathway occur in the ovary. Since steroid hormones are not sequestered in vesicles they are secreted upon synthesis. In males, testosterone is produced by the testes. The dashed line is intended to indicate that testosterone from the testes can be converted to estradiol or dihydrotestosterone in the brain and other organs (e.g., skin) that have the necessary enzymes: aromatase or 5alpha-reductase (enzymes are depicted above enclosed in an oval). The brain is also capable of synthesizing progesterone, testosterone and estradiol de novo

\section{Gonadal hormone influences}

Overview of gonadal hormones. The hormones progesterone, testosterone, and estradiol are steroidal, lipid/fat soluble molecules that are produced by the ovaries and testes (i.e., gonads) as part of the same synthetic pathway (Fig. 2). Gonadal activity is stimulated by the pituitary hormones luteinizing hormone (LH) and follicle-stimulating hormone (FSH) in males and females, although the exact details differ between the sexes. Estradiol and progesterone feed back to the hypothalamus and pituitary to regulate ovulation in females. In males, LH and FSH stimulate spermatogenesis and testosterone production to maintain a constant rate of sperm production. Importantly, estradiol is produced from testosterone (Fig. 2), in the ovary of females, and in the brains (and other organs) of males and females.

Organizational vs. activational influences of hormones. The structure, circuitry, and signaling pathways of the brain are "organized" during development due to early exposure to hormones, chromosomal differences, and/or sex differences in the placenta, resulting in the different types of sex differences described in Fig. 1. If there are "organizational" sex differences, males and females are different all of the time, independent of concurrent ovarian or testicular hormones. In addition, the brain can respond to circulating gonadal hormones, and since the testes and ovaries make different hormones, sex differences may be due to differences in the "activational" effects of these hormones. Finally, the brain may be both organized differently in males and females as well as differentially activated by hormones (or other external environmental and experiential factors) in a sex-specific way.

Sex chromosome influences

In order to determine whether a sex difference is due to sex chromosomes or gonadal hormones, a line of mice has been developed where the testis-determining gene, Sry, normally on the $Y$ chromosome, is not expressed and the Sry gene is inserted into an autosome [55]. This results in four possible sex chromosome / gonad combinations (i.e., the four core genotypes): XX (chromosomal and gonadal females), XXSry (chromosomal female and gonadal male), $X Y^{-}$(chromosomal male and gonadal female), and $\mathrm{XY}^{-}$Sry (chromosomal male and gonadal male). The four core genotype mice have been a useful tool to differentiate the role of sex chromosome complement from gonadal sex/hormone exposure during development on neurobiology and behavior [55], although the underlying mechanisms are still not fully understood, which represents a gap in knowledge. Evidence suggests that sex chromosome effects can emerge in the placenta and affect Xlinked genes expressed by the placenta that modify numerous proteins-including those mediating epigenetic processes-during fetal development [53]. Other sex chromosome effects emerge throughout development of the organism (and may themselves be a result of placental influences). Finally, sex chromosome effects may be mediated by $Y$ chromosome-linked genes including those encoding SRY, histone demethylases KDM5d, and UTY (encodes a histone demethylase), whereas some are due to female-biased expression of genes such as that encoding histone demethylase KDM5c.

\section{Autosomal influences}

Both environmental and genetic factors contribute to addiction vulnerability [56, 57]. Most genetic variation in humans is attributable to single-nucleotide polymorphisms (SNPs). These are positions on a DNA sequence at which two alternative bases occur in at least $1 \%$ of the human population. Synonymous SNPs alter the nucleotide without changing the resulting amino acid (i.e., a "silent" mutation). Non-synonymous SNPs alter the nucleotide and consequently change the resulting amino acid, an effect that typically has a greater impact on gene expression and function than synonymous SNPs. Additionally, SNPs can occur in gene promotors, exons, or in intergenic regions, which may differentially affect transcription, transcript stability, translation, protein folding, and function of the corresponding gene product. A great deal of effort has been made to associate SNPs in human genes with diseases (including substance use disorder) in order to identify causal factors. Although many associations have been found, this approach has yet to lead to the hoped-for therapeutic 
revolution. Indeed, this is an area that requires much additional research, as 1.42 million single nucleotide polymorphisms have been reported in the human genome [243].

Sex-dependent parent-of-origin allele bias. Although not usually considered in the study of sex differences, the sex of the parent can determine gene expression levels and patterns, and hence behavior, in offspring. Recently it has been shown that parental allele bias-typically due to canonical or noncanonical genomic imprinting [58] — can be preferentially expressed in one sex over the other in the offspring [54]. Parental bias has been demonstrated in a brain region-specific manner for the expression of several genes expressed in neural systems associated with feeding and motivated behaviors, which has strong implications for sex differences in addiction. Interestingly, there appears to be a preferential maternal contribution to gene expression in the developing brain and a major paternal contribution in the adult brain $[54,59]$.

\section{Epigenetic influences}

Acute epigenetic influences. Internal and external contingent factors can act on an organism such that sexually dimorphic traits are amplified or normalized. Epigenetics is one such contingent mechanism that links external factors (e.g., drugs of abuse, stress) to gene expression and function. Epigenetics includes transient, stable, and/or heritable changes in gene expression within mature, post-mitotic cells without alterations in the DNA sequence $[60,61]$. There are three primary epigenetic mechanisms: DNA methylation, histone post-translational modifications, and gene regulation by small non-coding RNAs.

DNA methylation occurs via a family of DNA methyltransferases (DNMTs) that primarily hypermethylate DNA at cytosine residues found in dinucleotide CpG sites. DNA methylation is involved in genomic imprinting, which is a process that allows for the selective (or biased) expression of only one parental allele in the offspring [62]. DNMTs methylate newly synthesized DNA strands to reproduce the DNA methylation pattern on the daughter cells [63], which allows methylation patterns to be maintained through mitosis. Hormones can modulate CpG methylation, with one example being that estradiol treatment significantly reduces the number of fully methylated sites, predominantly in intragenic regions, where DNA methylation is highest (for review, see ref. [64].

Histone post-translational modifications are mediated by histone deacetylases (HDACs) and histone acetylases (HATs). HDACs remove acetyl groups from lysine residues and thereby tighten the chromatin structure and reduce transcription, whereas HATs add acetyl groups to lysine residues and weaken the electric charge between histones and DNA [65]. This relaxes the tightly wound chromatin and is associated with increased gene expression.

Non-coding RNAs are a more recently discovered epigenetic mechanism. These include microRNAs (miRNAs), which are a class of non-protein coding RNA transcripts (19-24 nucleotides in length) that are highly expressed in the brain [66] and regulate gene expression at the post-transcriptional level [67]. Each miRNA targets $\sim 200$ mRNA transcripts [68] with diverse effects on gene expression including mRNA degradation, increased mRNA translation, chromatin remodeling, and DNA methylation [69]. Although RNAs were initially thought to be absent in the germline, more recent evidence shows that multiple populations of RNAs exist in sperm and oocytes [70], providing a method for the transfer of the epigenome to the offspring. There is evidence for significant sex differences in miRNA expression and function. It was shown that of 250 miRNAs assessed in neonatal mouse brain, approximately $2 / 3$ were expressed at different levels in males and females [71]. Of the miRNAs that differed by sex, half of them were due to gonadal steroid regulation and a third were due to bias in the sex chromosomes.

Importantly, all of the above processes are closely intertwined and can influence addiction in a sex-dependent manner as described in the next sections. For in-depth reviews of epigenetic mechanisms in the context of addiction (that do not specifically address sex as a biological variable) [72-75]. Furthermore, changes in histone modifications (e.g., acetylation, methylation) are necessary for DNA methylation and demethylation to occur [76]. Likewise, DNA methylation can regulate miRNA expression [77], and miRNAs can target mRNAs encoding histone-modifying enzymes such as HDACs, HATs, and methyltransferases [78]. Finally, each type of epigenetic mechanism can be regulated by sex: by sex chromosomes, gonadal hormones, or placental influences. For comprehensive reviews of these topics [53, 64]. An example of a tantalizing, but as yet unexplained, finding is that from Vilain and colleagues [79], who conducted genome-wide scanning of sex differences in methylation profiles of genes in the striatum and hypothalamus of neonatal and adult male and female rats. They found over 1000 genes that were differentially methylated in the striatum of adult, but not neonatal, males and females. They found sex differences where genes were methylated in one sex and not the other (bimodal distribution) and where one sex expressed methylation of a gene to a greater extent than the other (average/ mean difference). With only two individuals from each cohort analyzed, they were not powered to test whether there were differences in the frequency of methylation of individual genes in males vs. females (population differences). Understanding the functional significance of these different patterns of gene methylation is a gap in knowledge, as gene expression in the striatum is likely involved in processing information related to motivated behavior, disruption of which is a pillar of addiction.

Multigenerational and transgenerational epigenetic influences. Multigenerational inheritance derives from direct exposure to the drug. Thus, drug exposure in F0 males or females prior to pregnancy can have a direct impact on the germ cells, which go on to produce the F1 generation. Therefore, phenotypes found in F0 and F1 animals are considered multigenerational. In contrast, only those traits that persist into the F2 generation and beyond, which are not directly exposed to drug, are considered examples of transgenerational inheritance. This distinction is important for assessing the mechanisms underlying sex-dependent parent-of-origin epigenetic transmission [80] and impact on addiction vulnerability.

Epigenetic multigenerational or transgenerational inheritance is defined as "germline-mediated inheritance of epigenetic information between generations in the absence of direct environmental influences that leads to phenotypic variation" [81]. This phenomenon has been studied in great detail with regards to $X$ chromosome inactivation, but more recent pioneering work by Gregg et al. [54, 58, 59] has shown that imprinted genes inherited from maternal or paternal origin can be dependent on the sex of the offspring as well. By comparing parent-of-origin allelic gene expression within the hypothalamus and cortex of mice, they identified over 300 autosomal genes with sex-specific imprinting features [54]. At the molecular level, this is a striking example of how the same parents, environment, and gestational experience can yield significantly different outcomes in gene expression in sibling offspring that may predict long-term sex differences in disease risk and resilience. To date, there is still little known about how the sex of the parent and/or offspring in combination with environmental exposures such as drugs of abuse or stress directly contributes to drug addiction. Tantalizingly, aminergic systems and neural systems associated with feeding and motivated behaviors constituted the largest source of imprinting hotspots [59], providing a strong rationale for further study of these mechanisms in addiction models.

\section{Organizational and contingent factors interact}

The mechanisms described above interact at every developmental level-from preconception through gestation and through the lifespan-to produce sex-dependent traits that can contribute to 


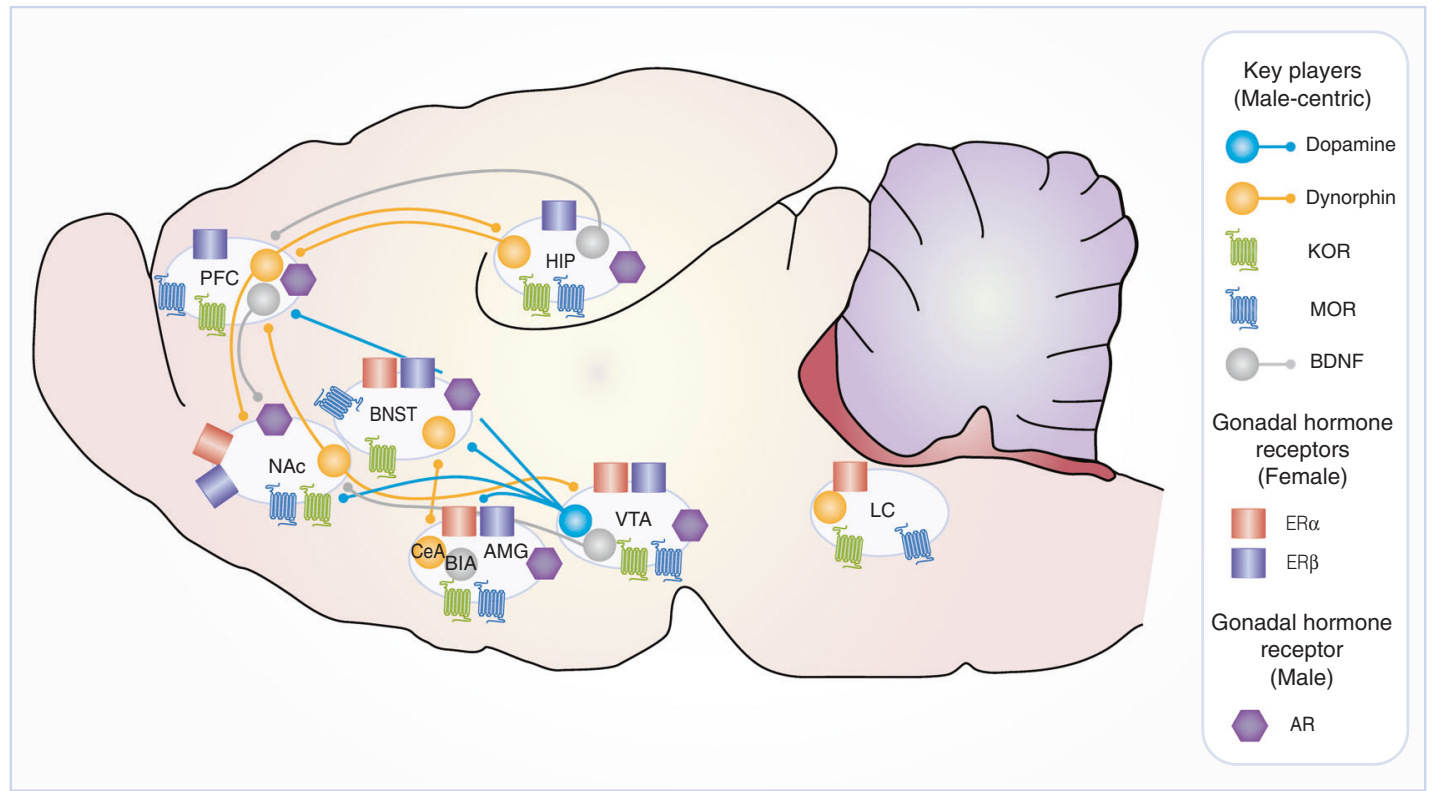

Fig. 3 Simplified neuroanatomical framework for major interactions between the four key players discussed in the section "Key players" (dopamine, DYN/KOR, MOR, and BDNF-data collected primarily from male rodents) and gonadal hormone receptors (data collected from females (ER $\alpha$ estradiol receptor alpha, $E R \beta$ estradiol receptor beta) or males (AR androgen receptor)) within neural circuitry implicated in addictive processes. Note that both males and females can produce testosterone and estradiol, although the divergent effects of these steroid hormones are mediated, in part, by sex differences in the levels and distribution of their cognate receptors [235]. Connections among brain regions utilizing the neuromodulators (dopamine, DYN, BDNF) are indicated when known [15, 184, 236, 237, 241, 242]. KOR and MOR receptor expression is indicated when known [160]. Gonadal hormone receptor expression is indicated when known [90, 91, 94, 238, 239]. AMG amygdala, AR androgen receptor, BIA basolateral nucleus of the amygdala, BDNF brain-derived neurotrophic factor, BNST bed nucleus of the stria terminalis, CeA central nucleus of the amygdala, ER $\alpha$ estradiol receptor alpha, ER $\beta$ estradiol receptor beta, HIP hippocampus, KOR kappa opioid receptor, LC locus coeruleus, MOR mu-opioid receptor, NAc nucleus accumbens, PFC prefrontal cortex, VTA ventral tegmental area

both addiction risk or resilience and to behavioral manifestations in each of the three main stages of addiction. It is essential to understand that these sex-dependent mechanisms more often than not result in normalizing behavioral outputs between males and females. As such, males and females typically do not drastically differ in their behavioral responses to drugs of abuse. However, given that the underlying molecular and genetic mechanisms producing behavior can be different between the sexes, it behooves us to conduct our experiments in both males and females as we drill down into mechanistic understanding of addiction.

The following sections apply this framework for sex/gender differences to focus on four neural systems that are known to be key players in addictive processes: dopamine, MORs, dynorphin (DYN)/KORs, and BDNF. Figure 3 is a highly simplified schematic of how these players overlap within neural circuitry related to reward and addictive behavior, while simultaneously showing the location of estrogen and androgen receptors. Implicit in this figure is the caveat that the data supporting the specific involvement of these neural circuits in reward and motivated behavior was collected almost exclusively in males. Our goal is to describe what is currently known about links between sex differences and addictive behavior (focusing on opioids and psychostimulants) in each of these systems within the conceptual framework of the organizational and contingent mechanisms described above. Our goal is not to provide comprehensive coverage of these mechanisms and processes-we think this issue of Neuropsychopharmacology reviews will satisfy that. Rather, we are focusing on what is currently known in the addiction space. In some instances there are no published studies (to our knowledge) directly linking a particular sex-dependent mechanism with substance use disorder per se. However, there is strong evidence for sex differences in the developmental origin and expression of the neural systems that could enable sex differences in addictive behavior. Our hope is that this review will highlight these gaps in knowledge and stimulate experiments to fill the gaps, which will ultimately translate to more effective, sex-specific preventative measures and treatments for addiction.

\section{Key players}

Dopamine. The mesocorticolimbic dopamine system is inextricably involved with each phase of the addiction cycle [35]. At numerous points in dopamine signaling, including synthesis, release, reuptake, and postsynaptic responses, there are examples of sex-dependent effects that can be-but are not alwaysrelated to circulating gonadal hormone modulation. We discuss below and have graphically summarized known sex-dependent mechanisms underlying dopamine signaling in Fig. 4.

In dopaminergic neurons, the enzyme tyrosine hydroxylase (TH) converts tyrosine to DOPA, and dopa-decarboxylase (DDC) converts DOPA to dopamine. Release of dopamine results in activation of D1-like and D2-like receptors (D1r, D2r) found both pre-synaptically (D2r) and post-synaptically (D1r and D2r) on distinct populations of neurons. The presynaptic dopamine transporter (DAT) is primarily responsible for rapid clearance (reuptake) of dopamine from the extracellular space. Consequences of D1r and D2r activation include a myriad of intracellular signaling cascades [82]. Numerous additional genes and factors modulate this basic synthesis pathway, and there is ever increasing data suggesting that sex plays an important role in their regulation and role in behavior [26].

Organizational influences and activational influences of gonadal hormones: Males but not females over-produce D1 $r$ and D2 $r$ in the striatum during development, and the receptors are pruned prior to adulthood in males $[83,84]$. Neither the over-production of receptors, the pruning of dopamine receptors in males, nor the lack of over-production in females, is due to the presence of 


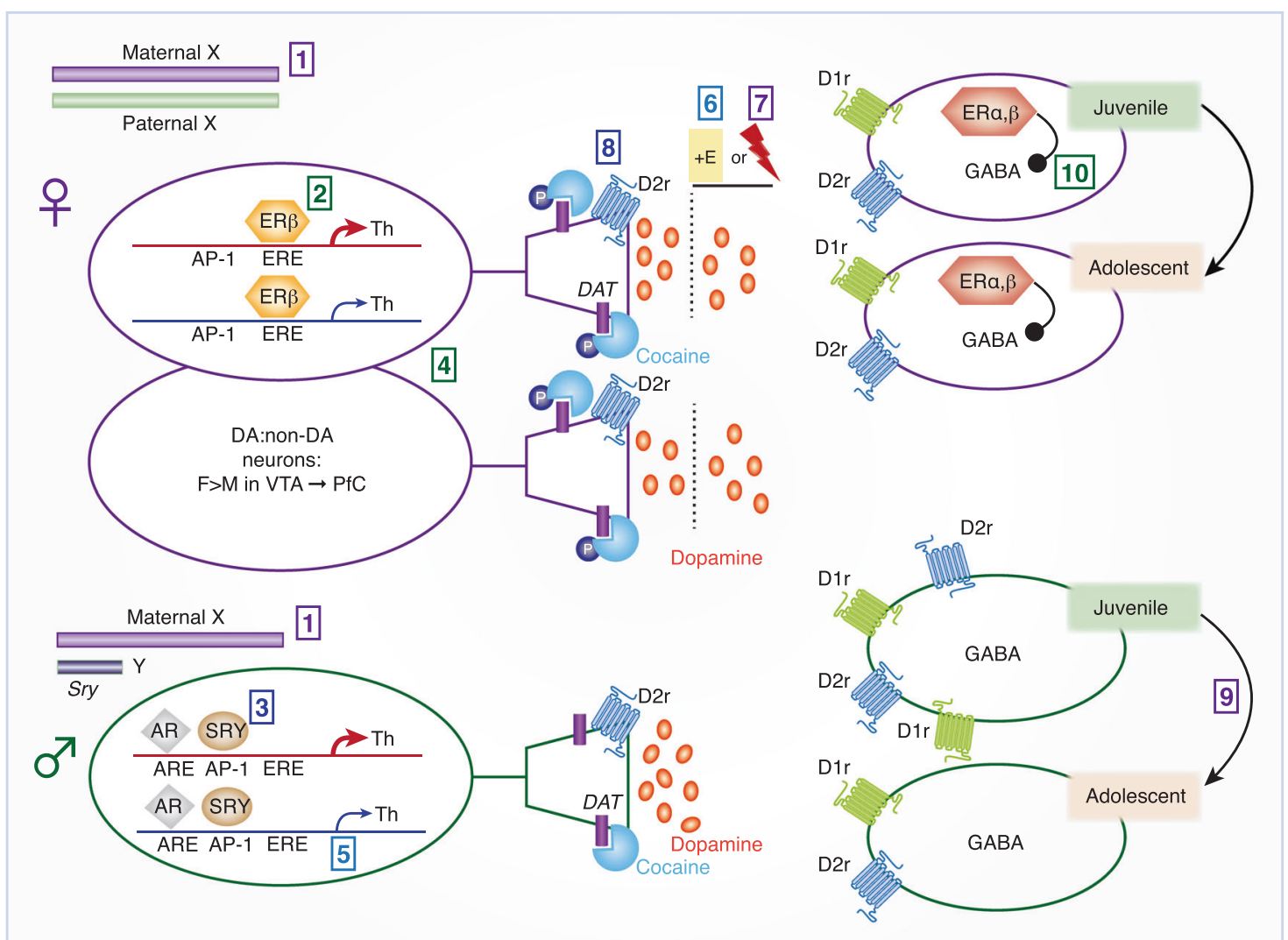

Fig. 4 Simplified composite schematic of organizational and contingent mechanisms leading to sex differences in dopaminergic signaling within limbic brain regions. To be inclusive, the figure collapses data from ventral tegmental area $\rightarrow$ nucleus accumbens and prefrontal cortex. Known distinctions between these projections are indicated in this figure legend and in the figure. The information in this figure is based on work reported in the section "Dopamine", which is meant to highlight research that demonstrates preclinical connections to psychostimulant and/or opioid addiction-related behaviors. [1] In embryonic mice, sex chromosome complement, but not gonadal sex, determines TH expression in midbrain dopamine neurons. Chromosomal males have greater TH expression than chromosomal females, regardless of gonadal hormones [119]. [2] ER $\beta$ is co-localized in TH-expressing neurons of the ventral tegmental area in adult males and females and is thought to stimulate TH expression in females [124]. [3] In adult males, ARs and SRY are necessary for maintenance of TH expression. SRY knockdown decreases TH expression in males, but not females [120]. [4] Females have a higher ratio of dopaminergic to non-dopaminergic neurons projecting from the ventral tegmental area to the prefrontal cortex [96]. Whether this is true for projections to the nucleus accumbens is not known. [5] There is a maternal allele bias in the Th gene in select brain regions, not including the ventral tegmental area [58]. [6] Estradiol increases dopamine release in the striatum of females only, and it requires a lack of testosterone exposure during development [87, 88]. [7] At baseline, there are higher extracellular dopamine levels in the male, compared to the female, striatum [98, 240]. However, baseline ventral tegmental area activity and phasic dopamine release is similar between the sexes in the nucleus accumbens [118]. Electrically stimulated phasic dopamine release is higher in estrous females (when estradiol levels are high) compared to males or females in low-estradiol stages [100, 101, 103, 118]. [8] Estrous-associated increases in ventral tegmental area firing and dopamine release increase phosphorylation of DAT at threonine 53 (Thr53), which increases the affinity of cocaine for DAT. This results in a greater cocaine-induced dopamine release in females during estrous [118]. [9] Males, but not females, over-produce D1 $r$ and D2r in the striatum early in development [84]. D1rs, at least, are pruned in males during adolescence via actions of microglia [86]. D1r and D2r are primarily localized to distinct populations of neurons, but for graphical simplicity in this figure, we included them on the same neurons. [10] ER $\alpha / \beta$ interact with mGluRs on neuronal membrane via caveolin to inhibit GABAergic nucleus accumbens medium spiny neurons. This decreases inhibitory input to dopamine neurons in the ventral tegmental area and allows for greater dopamine release [90, 94]. AR androgen receptor, DAT dopamine transporter, D1r dopamine D1 receptor, D2r D2 receptor, ER estrogen receptor ( $\alpha$ or $\beta$ forms indicated when known), SRY sex-determining region $\mathrm{Y}$, TH tyrosine hydroxylase

pubertal hormones [85]. A recent study has demonstrated that, in the nucleus accumbens of both male and female rats, D1rs show peak expression during peri-adolescence or early-adolescence followed by a subsequent reduction to adult D1r levels [86]. In this study, the mechanism underlying D1r pruning in the nucleus accumbens is sex-specific: in males only, elimination of D1rs occurs via microglia-mediated phagocytosis. Taken together with the earlier studies, it is possible that interactions between hormones secreted during the perinatal period and microglia work to regulate dopaminergic synaptic maturation and plasticity in a sex-dependent manner.

An early study showed that ovarian hormones regulate dopamine release in tissue from dorsal striatum of females, but not males. This sensitivity to estradiol is mediated by lack of testosterone during the early period of sexual differentiation and the presence of ovarian hormones at puberty $[87,88]$. The same pattern of organizational influences of gonadal hormones on estradiol-enhancement of self-administration of cocaine in females rats has also been found [89]. Thus, there are active organizational influences of gonadal hormones on the ascending dopamine system in males early during neonatal development and in females during puberty.

The effect of estradiol in dorsal striatum of adult females is mediated by estradiol receptors (ERs) on medium spiny GABA neurons that attenuate GABA release, thereby enhancing dopamine release by a decrease in inhibition [90-93]. The Mermelstein 
laboratory has shown that ER alpha (ERa) and beta (ER $\beta)$ couple via caveolin to specific metabotropic glutamate receptors (mGluR) in dorsal striatum to indirectly modulate dopamine release $[90,93-95]$.

Furthermore, there is expression of $E R a, E R \beta$, and androgen receptors (ARs) in midbrain dopamine neurons projecting to the prefrontal cortex that is not only sex-dependent, but also dependent on the specific afferent targets [96]. Indeed, the ratio of dopaminergic to non-dopaminergic neurons projecting from the midbrain to the prefrontal cortex shows a strong sex difference: in males, about $30 \%$ of meso-prefrontal projections are dopaminergic, whereas in females the proportion is closer to $50 \%$ [96]. Whether this anatomical sex difference is hormonedependent is not known, but it strongly suggests that the effects of drugs of abuse on dopamine-dependent behaviors involving the prefrontal cortex will be sex-dependent. It is also not known whether there is a sex difference in the ratio of dopaminergic to non-dopaminergic neurons projecting from the midbrain to the nucleus accumbens.

In experiments using in vivo microdialysis with ovariectomized (OVX) female and castrated (CAST) male rats, basal extracellular dopamine levels collected over $10 \mathrm{~min}$ are significantly lower in the nucleus accumbens and dorsal striatum of females compared to males $[97,98]$. In females, extracellular dopamine varies with the estrous cycle [97] and is dependent on the actions of estradiol in the striatum. Estradiol acts directly in dorsal striatum to enhance stimulated dopamine release in OVX female, but not CAST male rats $[97,99-102]$. In possible contrast to the above results using microdialysis, which provides a slower time course of extracellular dopamine release, in vivo and in vitro experiments in rats using fast scan cyclic voltammetry, which measures phasic dopamine release in real time, has shown that electrical stimulation of the ventral tegmental area and cocaine-induced dopamine release and uptake rates are greater in the female, compared to the male, striatum-regardless of estrous cycle stage, which may underlie the lower basal dopamine concentrations found with microdialysis [103].

There are also sex differences in dopamine receptors in dorsal striatum and frontal cortex [104]. Estradiol rapidly down-regulates D2 $r$ binding in the dorsal striatum of female, but not male rats [105]. In the striatum of female rats, estradiol also regulates D1r binding $[106,107]$.

Sex differences and effects of ovarian hormones on selfadministration of cocaine and methamphetamine have been extensively documented [26, 108-113]. The sex differences in acquisition and the effects of estradiol to enhance the motivation to self-administer cocaine are due to both organizational and activational effects of gonadal hormones [89, 114]. In studies examining sex differences in the choice of cocaine over sucrose pellets, over $50 \%$ of females chose cocaine as compared to $<20 \%$ of males [114, 115]. Subsequent analysis indicated that ovarian hormones no longer influence motivation for cocaine in females in which drug taking is well established, whereas the estrous cycle continues to modulate motivation for pellets [115]. Indeed, a thorough examination of cocaine dose-effect functions in intact, gonadectomized, and hormone-replaced rats found no effect of gonadal hormone manipulations when cocaine taking is established with a high dose of cocaine such as $1.0 \mathrm{mg} / \mathrm{kg} /$ infusion [116]. The authors conclude that behavioral training history, drug dose, and schedule of reinforcement are important variables in studies of sex and gonadal hormone effects on drug selfadministration. Following extinction of drug taking, cue-induced reinstatement is greater in women than in men and sensitive to ovarian hormones in animal models [44, 117, 244, 245]. Thus, gonadal hormone-dependent effects on addiction are sensitive to the stage of addiction.

To probe more deeply into the neural mechanisms underlying the responses of males and females to cocaine, a recent paper from Calipari et al. [118] looked at the functional circuit mediating cocaine reward in mice. They found that basal VTA dopamine neuron activity and dopamine release in the nucleus accumbens is similar between male and female mice, except during estrous when firing rate and dopamine release in slices is significantly higher in females. In a novel finding, they show that increased dopamine neuron activity leads to increased phosphorylation of the DAT at threonine 53, which increases the affinity of DAT for cocaine. As such, cocaine-induced dopamine release and cocaineinduced conditioned place preferences are higher in estrous females compared to males and non-estrous females. Although this study did not directly manipulate gonadal hormones, they confirmed that estradiol and progesterone levels are higher during estrous in their study, and they found a significant positive correlation between estradiol level (but not progesterone) and inhibition of dopamine uptake, supporting the argument that estradiol is responsible, at least in part, for the increases in: dopamine neuron firing, dopamine release, phosphorylation of DAT, and reward-related effects of cocaine.

Organizational influences: sex chromosomes: Using the four core genotype mouse model, the Arnold laboratory demonstrated that embryonic mesencephalic neuronal cultures taken from each core genotype developed different levels of $\mathrm{TH}$ immunoreactivity depending on sex chromosome complement, but not gonadal sex (i.e., not hormones) [119]. Specifically, chromosomal males $\left(X Y^{-}\right.$Sry and $\left.X Y^{-}\right)$had significantly higher levels of TH immunoreactivity than chromosomal females. This is broadly consistent with findings in adult rats, in which the number of $\mathrm{TH}$-positive neurons was $20 \%$ less in the female substantia nigra compared to the male [120].

Additional work in humans and adult rodents has shown: 1. SRY co-expresses within a sub-population of $\mathrm{TH}$-positive neurons in the human and mouse male, but not female, substantia nigra [120, $121], 2$. In human-derived in vitro culture systems, SRY knockdown decreases $\mathrm{TH}, \mathrm{DDC}$, dopamine $\beta$-hydroxylase $(\mathrm{DBH})$, and monoamine oxidase-A (MAO-A) expression, and 3. Using antisense oligodeoxynucleotides to knock down Sry expression in the rat substantia nigra causes a significant decrease in TH expression (no overall effect on neuronal number) and emergence of motor deficits in male rats [120].

When taken with the four core genotype embryonic mouse results, the data suggest that early developmental expression of $\mathrm{TH}$ is primarily hormone-independent, but adult expression involves, in part, induction and maintenance of TH by SRY and androgen receptors in males [122] and by estrogen receptors in females. Indeed, immunoreactivity for ERa, ER $\beta$, and ARs has been localized to subsets of rat ventral midbrain dopamine neurons [123, 124]. Likewise, short-term administration of estradiol benzoate to OVX females increases levels of TH in dopaminergic neurons [125].

The Taylor lab used the four core genotype mice to demonstrate effects of the sex chromosomes on goal-directed and habit-driven behaviors. They found that XX mice (chromosomal female) showed faster food-reinforced instrumental habit formation than $X Y$ (chromosomal male) mice, regardless of gonadal phenotype [126]. Interestingly, these findings seem inconsistent with a separate study in which it was shown that after moderate instrumental training for alcohol reinforcement, $X Y$ mice (chromosomal male) became insensitive to outcome devaluation, indicating habitual responding for alcohol, whereas $X X$ mice (chromosomal female) remain sensitive to outcome devaluation, indicating goal-directed behavior [127]. Taking these findings together, it is possible that sex chromosome complement affects habit formation depending on the reinforcer in both females and males. The neurobiological mechanisms underlying these behavioral outcomes were not investigated, but are likely due to sex differences in mesocorticolimbic and nigrostriatal dopaminergic signaling. 
Organizational influences: autosomal: There is a maternal allele bias in many of the genes involved in dopamine signaling. These include genes encoding tyrosine hydroxylase $(T h)$, dopa decarboxylase $(D d c)$, and transforming growth factor beta 1 -induced transcript 1 (Tgfb1i1l; acts as an inhibitor of the dopamine transporter, DAT), and cyclin-dependent kinase inhibitor $1 \mathrm{C}$ [Cdkn1c; enhanced maternal care during early life increases $C d k n 1 c$ expression in the maturing ventral tegmental area accompanied by enhanced survival of dopamine neurons [128]]. Of note, parental (typically maternal) allele bias is brain regionspecific, and has been detected primarily in the arcuate nucleus, dorsal raphe nucleus, and locus coeruleus, but notably not the ventral tegmental area [58]. The functional significance of this depends on many factors, including which brain regions and cell types express the maternally biased allele and whether genetic or environmental perturbations of the mother modulate DNA methylation patterns and histone modifications of the genes. This complex mechanism allows for an infinite combination of individual risk/resilient factors that warrant further study.

Organizational influences: epigenetics: Parental (FO) cocaine exposure: In a mouse model of maternal cocaine exposure, in which dams were injected with cocaine during the second and third trimesters of gestation, significant epigenetic alterations were found in hippocampal pyramidal cells of the male offspring around the perinatal (postnatal day 3 ) and prepubertal (postnatal day 30) periods [129]. In neonatal offspring of cocaine-exposed mothers, there was a decrease in global methylation levels, whereas in prepubertal offspring, overall DNA methylation was significantly increased compared to matched controls. These methylation changes were associated with alterations in the expression of the DNA methyltransferases, DNMT1 and DNMT3b, in hippocampal pyramidal cells. Importantly, instances of both hypermethylation and hypomethylation were observed at both time points in the offspring following maternal cocaine exposure. This suggests that some genes are activated and some repressed by chronic maternal cocaine exposure. Although it is not specifically known how this multigenerational effect on DNA methylation regulation occurs, one likely explanation is that gestational exposure to cocaine altered the epigenetic landscape in the placenta that had dominant effects on the male offspring [53]. However, this remains to be directly tested. A second fascinating gap in knowledge is understanding the mechanism by which changes in methylation status vary in male offspring at perinatal and prepubertal developmental time points.

In the 1980s there was considerable concern about children born to mothers who were addicted to crack cocaine. Research demonstrated that while these effects can be subtle, prenatal cocaine exposure puts adolescents at risk for substance use disorders, with most studies finding males at greater risk than female offspring $[130,131]$. There are also effects of prenatal cocaine exposure on the neurochemistry of the brain and the behavior of the offspring that are sex-specific and depend on when during development exposure to cocaine occurs as well as when the outcome is assessed [131-133]. Following cocaine exposure to rats at a time equivalent to the last trimester in humans, there is a decrease in functional dopaminergic activity due to a de-coupling of the D1 $r$ from its second messenger system in the prefrontal cortex and increased serotonin transporter in the dorsal raphe and serotonin-signaling-dependent behavior of males but not females [133, 134].

When sires were allowed to self-administer cocaine vapor prior to mating, there were substantial developmental impacts on brain size, attention, and memory processes in the offspring, particularly in females [135]. Mechanistically, this study also showed that chronic cocaine exposure in the sires significantly decreased expression of Dnmt1 and increased expression of Dnmt3a in the germ cell-rich seminiferous tubules of the testis. Since DNMT enzymes are essential for generating and maintaining parental gene imprinting in germ cells, these findings suggest that paternal cocaine exposure may exert its multigenerational effects by interfering with gene-imprinting patterns in male gametes.

Although there are numerous studies, particularly from the Byrnes lab [136, 137], that explored multigenerational effects of parental opioid exposure, sex differences in direct effects on dopamine systems were not specifically reported. As such, this represents a gap in knowledge open to investigation.

\section{Mu-opioid receptors}

The endogenous opioid peptides beta-endorphin, prodynorphin, enkephalin, and orphanin/nociception comprise a class of naturally occurring compounds that bind to and activate one of four known opioid receptors: mu, delta, kappa, or nocicepton opioid receptors (MOR, DOR, KOR, NOR, respectively). These are 7transmembrane, G-protein-coupled cell surface receptors encoded by distinct genes (Oprm1, Oprk1, Oprd1, and Oprl1, respectively). Opioid receptor genes are highly conserved in their 7transmembrane domain, but not in their amino and carboxyl termini, allowing for different ligand binding ability and downstream signaling. Opioid receptor genes can also be alternatively spliced, have alternative promoters (Oprm1, Oprk1), and/or have alternative polyadenylation sites (Oprk1), all of which can lead to multiple mRNA isoforms (see [138].

Organizational influences and activational influences of gonadal hormones. There are sex differences in MOR receptor density in midbrain and dorsal striatum that are modulated by intrauterine position, suggesting that intrauterine exposure of female mice to androgens from males adjacent in utero has organizational effects. If a female mouse is between two females in utero, the MOR density in the midbrain is significantly lower than a male between two females (0 M) [139].

There are effects of estrous cycle on heroin self-administration, with females reducing intake during proestrus, but exhibiting overall greater heroin intake than males [140]. Female rats also acquire heroin intake more rapidly than males [141, 142]. In OVX females, estradiol treatment increases acquisition of heroin selfadministration and heroin intake [143]. In apparent contrast to results with heroin self-administration, it has been shown that male rats initially self-administer more oxycodone than females [29]. This sex difference in acquisition disappears after several days of self-administration behavior, with males and females taking similar amounts of oxycodone during subsequent sessions under fixed ratio (FR) 1, 2, and 5 schedules of reinforcement. The initial sex difference in oxycodone intake was not due to pharmacokinetics, as plasma and brain levels of drug were the same in both sexes. Furthermore, exposure to oxycodone self-administration did not disrupt the estrous cycle, although the effect of gonadal hormones on behavior was not directly tested. Taken together, differences in pharmacological profiles of different opioids may amplify or inhibit sex differences in underlying MOR signaling.

Organizational influences: sex chromosomes. Adult, chromosomal female (XX and XXSry) mice were more sensitive to both thermal and chemical painful stimuli than chromosomal male mice [144]. All mice were gonadectomized as adults, which removed activational effects of gonadal hormones as a potential mechanism. However, it is not possible to dissociate sex chromosome effects from effects mediated by the placenta since the placenta is determined by the fetal sex chromosomes and plays a role in mediating the effect of XX chromosomes on development [53]. Morphine had similar antinociceptive effects in the hot plate test in chromosomal females and males, although the absolute magnitude was greater in $X Y$ mice, which was likely a result of decreased baseline sensitivity to thermal pain in these mice. Furthermore, similar levels of tolerance to the analgesic effects of 
morphine were observed, regardless of chromosomal or gonadal sex.

Organizational influences: autosomes. A single-nucleotide polymorphism (SNP) in exon 1 of the MOR gene (Oprm1), in which an adenine-to-guanine substitution (A118G) exchanges an asparagine for an aspartic acid at a putative $\mathrm{N}$-glycosylation site, is common in persons of European (15-30\%) and Asian (49-60\%) ancestry. Genetic association studies suggest that the Oprm1 A118G genotype confers an increased risk of heroin use disorder [145].

A knock-in mouse model was generated that possesses the mouse-equivalent SNP in the MOR gene [146] in order to study the functional consequences of this SNP. Both male and female mice homozygous for the G/G allele showed decreased MOR mRNA and protein in numerous brain regions, including, but not limited to, the VTA, nucleus accumbens, cortex, and hypothalamus. However, there were moderate sex differences in DAMGO-stimulated $\left[{ }^{35} \mathrm{~S}\right]$ GTPYS binding, which is a measure of MOR-mediated G-protein activation [147]. For example, male $G / G$ mice showed significantly higher net DAMGO-stimulated $\left[{ }^{35} \mathrm{~S}\right] \mathrm{GTP}$ S binding than female G/ $\mathrm{G}$ mice in the cingulate cortex, striatum (including nucleus accumbens core), and amygdala, suggesting that-despite lower overall levels of MOR-male G/G mice showed a stronger response to the same amount of stimulation.

The mechanisms underlying these sex differences in Oprm $1 \mathrm{G} / \mathrm{G}$ mice are not known but may involve interactions with gonadal hormones. It has been shown that, during proestrus-when estradiol levels are highest-female rats have decreased MOR immunoreactivity in portions of the periaqueductal gray (PAG) compared to males [148]. The PAG is necessary for morphine analgesia and sex differences therein. It is also known that the developmentally regulated and sexually dimorphic methyl-CpGbinding protein 2 (MeCP2) is involved in epigenetic regulation of the Oprm1 promoter [149], raising the possibility of differential epigenetic regulation of $A / A$ and $G / G$ genotypes in a sexdependent manner. However, no studies to date have directly examined these possibilities in Oprm1(A118G) mice.

Interestingly, female, but not male, $G / G$ mice failed to express conditioned place preferences to morphine, and morphinedependent female $\mathrm{G} / \mathrm{G}$ mice showed significantly reduced naloxone-induced conditioned place aversions compared to their A/A counterparts [146]. This effect was not due to a reduction in somatic morphine withdrawal signs in female $G / G$ mice, as somatic signs were similar between $A / A$ and $G / G$ females. This sex difference is consistent with the finding that female $G / G$ mice showed reduced MOR activation in brain regions known to be essential for reward-related and aversion-related effects of drugs of abuse [147]. Despite sex differences in morphine reward and dependence in Oprm1(A118G) mice, no sex differences were observed in heroin self-administration [150]. It is possible that the sex differences observed in the Mague et al. [146] study are drugspecific, or that the strength of the reinforcer in the selfadministration study (heroin access for 4-h per day) overcame moderate sex differences in MOR signaling. Alternatively, since the neural circuits regulating place conditioning and acquisition and escalation of operant drug taking are not identical, the sex differences identified in Mague et al. [146] may be specific to those circuits. Regardless, these kinds of preclinical findings underscore the importance of powering human studies to detect sex differences.

Organizational influences: epigenetics

Parental (F0) opioid exposure has sex-dependent effects on offspring: A series of studies from the Byrnes lab $[137,151-155]$ examined the impact of adolescent morphine exposure in female rats (F0) on behavioral and molecular measures in the F1 offspring at different developmental times.
One purpose of the adolescent exposure paradigm was to avoid direct modulation of the developing placenta and fetus. However, it was not directly tested whether pre-gestational environmental manipulations trigger cascades of molecular genetic events that ultimately impact placental function and fetal development. Dams-to-be were administered escalating-dose morphine for 10 days during early adolescence and then remained drug-free until mating in adulthood. The Byrnes' lab's behavioral findings in adult F1 females from morphine-treated dams relative to salinetreated dams include: anxiogenic effects in the elevated plus maze and the open field novel environment test; a more rapid induction of morphine sensitization; significantly enhanced sensitivity to morphine-induced conditioned place preferences; decreased morphine self-administration during acquisition and a reduced breakpoint when morphine was available under a progressive ratio schedule of reinforcement; and blunted morphine-induced reinstatement of drug seeking after extinction. Their findings in adult F1 males include: enhanced expression of morphine locomotor sensitization; increased sensitivity to the analgesic effects of acute morphine; more rapid development of analgesic tolerance following chronic morphine treatment; and (similar to female F1s) blunted morphine-induced reinstatement of drug seeking after extinction of morphine self-administration. Their molecular findings in adult F1 females from morphine-treated dams relative to saline-treated dams include: higher MOR expression, decreased myelin basic protein, and a slight decrease in the synaptic plasticity gene, Zwint in the nucleus accumbens, as well as a trend for a decrease in MOR expression in the ventral tegmental area.

The point in development at which alterations in opioid sensitivity emerge in male and female $\mathrm{F} 1$ offspring of morphineexposed dams is relatively unknown. If significant sex differences are observed before puberty, they are likely not the result of circulating gonadal hormones mediating multigenerational effects in F1 offspring. Rather, the multigenerational impact on behavior would be due to early developmental effects that may or may not involve gonadal hormones. In support of this latter mechanism, it was shown that pre-pubescent male, but not female, F1s from dams who were administered morphine during adolescence had increased morphine-induced sedation and decreased morphineinduced corticosterone secretion, as well as significant increases and decreases in arcuate POMC and ventral tegmental area Oprm1 gene expression, respectively [151].

Finally, some effects of maternal opioid exposure were transgenerational, as they were found in the F2 generation. For example, F2 females of F0 dams exposed to morphine during adolescence showed reduced morphine self-administrationsimilar to effects observed in the F1 generation [137]. Expression levels of a number of synaptic plasticity genes were examined in the nucleus accumbens of F1 and F2 males and females. Although significant effects of F0 dam morphine exposure were observed on gene expression, neither the functional significance nor the mechanisms underlying the differences are yet understood.

There is also evidence that opioid exposure in male rats can have multigenerational effects, including significant endocrine alterations and enhanced anxiety-like behavior in both male and female offspring $[156,157]$. Moreover, an acute bolus of morphine administered to males just prior to mating resulted in male, but not female, offspring with a significantly enhanced sensitivity to the antinociceptive effects of morphine [158].

Dynorphin and kappa opioid receptors

Dynorphins are a class of opioid peptides that arise from the precursor protein prodynorphin and act as endogenous ligands at KORs [159]. In the context of addiction, DYN and KORs are expressed throughout brain regions involved in affect, cognition, and motivated behavior, including the ventral tegmental area, nucleus accumbens, prefrontal cortex, hippocampus, dorsal 
176

striatum, amygdala, bed nucleus of the stria terminalis, locus coeruleus, substantia nigra, dorsal raphe nucleus, and hypothalamus [160, 161]. KOR activation in these regions modulates motivated behavior and affective state [38, 162]. Within the mesocorticolimbic system, KORs are expressed on dopamine neurons, and activation inhibits dopamine neuron firing and dopamine release [163-165], most likely by stimulating KORs on dopaminergic afferents from VTA neurons [166].The human gene encoding DYN (Pdyn) contains four exons, as well as a noncanonical activating protein 1 (AP-1)-like site in its promoter region, which is a target for Fos/Jun trans-activation, as well as three cAMP response elements (CRE) elements, which are targets of CREB-mediated transcriptional activation [167, 168].

In males, activation of KORs produces depressive-like and anxiogenic behaviors [165, 169, 170], encodes the dysphoric component of stress [38, 171], and can promote drug-seeking behavior [172-175]. Likewise, KOR blockade has antidepressant and anxiolytic effects [176-178], attenuates aversive states associated with cocaine withdrawal [179], and attenuates drugseeking behavior [46, 180,181]. These findings are consistent with observations that KOR agonists produce dysphoric and depressive-like states in men [182]. Only recently has the effect of KOR activation on affective state been measured in females, and it was shown that female rats are significantly less sensitive than males to the anhedonic effects of exogenous KOR activation, as measured with intracranial self-stimulation (ICSS) [183]. The anhedonic response to KOR activation did not vary with estrous cycle stage or after castration of male rats, suggesting that circulating gonadal hormones do not modulate KOR-mediated negative affective states.

Although there is little direct evidence linking sex differences in DYN and KOR systems to addictive behaviors, there is increasing evidence for sex differences in the role of KORs in mediating stress responses and affective states in preclinical animal models [184]. Given the importance of stress reactivity to addiction $[22,38]$, this evidence may help us understand, on a mechanistic level, why addiction is experienced differently in men and women.

Organizational influences and activational influences of gonadal hormones. There is substantial evidence for organizational and activational roles of gonadal hormones in mediating effects of KORs [185-187]. The most straightforward manner in which gonadal steroids might influence KOR function is via transcriptional mechanisms involving steroid hormone receptor binding to estradiol or androgen response elements (ERE, ARE, respectively) found in gene regulatory regions [188-190]. For example, estradiol has been shown to decrease DYN expression in the arcuate nucleus of the hypothalamus in wild-type but not ERa-/- mice through an ERE-dependent pathway [189]. There is also evidence that testosterone can regulate DYN expression. In castrated Romney Marsh rams, testosterone treatment increases Pdyn mRNA in the supraoptic nucleus and the bed nucleus of the stria terminalis during the breeding season [191].

A more indirect mechanism for gonadal hormone control of gene expression is through modulation of transcription factor activity. For example, the Pdyn gene contains cAMP response element (CRE) sequences in its promoter that bind the transcription factor CREB $[167,192]$. Estradiol treatment has been shown to increase CREB phosphorylation at serine residue 133 in the anteroventral periventricular nucleus, resulting in elevated pCREB in approximately $25 \%$ of DYN-positive neurons in this region [193].

Organizational influences: sex chromosomes. Using the four core genotype mouse model, in which all 4 genotypes were gonadectomized to remove circulating gonadal hormones, it was shown that expression of Pdyn, the gene encoding DYN, was higher in the striatum of chromosomal female ( $X X$ and $X X$ Sry) mice compared to chromosomal male $\left(X Y^{-}\right.$and $X Y^{-}$Sry) mice [194].
Furthermore, $\mathrm{XX}$ mice had higher Pdyn expression than $\mathrm{XY}$ or $\mathrm{XO}$ mice, indicating that the sex chromosome effect is the result of differences in the number of $X$ chromosomes rather than a factor on the $Y$ chromosome. Although not completely understood, this is likely due to sex differences in the expression of $X$ gene(s) that escape inactivation rather than hemizygous exposure in males of specific $X$ alleles, because this study utilized mice that have identical X chromosomes [194]. The functional significance of higher striatal Pdyn gene expression in chromosomal females is unknown. First, it is not known whether this finding translates to increased DYN peptides, release, or postsynaptic function. Second, the impact of circulating gonadal hormones is unknown, as these were effectively removed by gonadectomy in this study.

Organizational influences: autosomal. Sex-linked polymorphisms in the Pdyn gene have been associated with increased vulnerability to develop substance used disorders [17]. Specifically, two SNPs, rs 1997794 in the promoter and rs1022563 in the $3^{\prime}$ UTR region of the Pdyn gene have been shown to be significantly associated with opioid dependence in women but not men in a Chinese population, suggesting that these SNPs confer an increased risk for women [17, 195]. In European Americans, SNPs rs1022563, rs910080 and rs199774 have been shown to be significantly associated with an increased risk for opioid use disorder in both men and women. However, the odds ratio was higher in women compared to men [195]. In contrast, no significant associations with SNPs in the Pdyn gene have been found in African Americans [195]. SNPs in the 3' UTR of the Pdyn gene (rs910080 and rs2235749) are associated with decreased DYN expression [196]. This raises the possibility that DYN is decreased in women with Pdyn SNPs associated with increased risk of developing opioid dependence. Future studies should determine why the association of these SNPs with opioid dependence is higher in women and also whether their presence can have predictive value in specific subpopulations of women.

Organizational influences: epigenetics. Although there is strong evidence for epigenetic regulation of Pdyn via DNA methylation and miRNAs within limbic brain regions [197, 198], and Oprk1 via histone acetylation (acetylated histone H3 Lysine9) in the spinal cord [199], there is no direct evidence (to our knowledge) of sex differences in epigenetic regulation of either Pdyn or Oprk1.

Brain-derived neurotrophic factor (BDNF) and TrkB receptor BDNF belongs to a group of secreted homodimeric proteins that are critical regulators of cell growth, survival, and differentiation during nervous system development and play important roles in activity-dependent modeling of neural function in the adult brain (for review, see [200]. There is a large body of evidence implicating BDNF in both psychostimulant and opioid reward, reinforcement, reinstatement of drug seeking, and incubation of drug craving, as reviewed in [201, 202].

BDNF exerts its biological effects primarily through binding to the high-affinity tropomyosin receptor kinase $B(T r k B)$ receptor as well as to the low-affinity p75 neurotrophin receptor (p75NTR) [203]. Rodent BDNF genes encode eight two-part transcripts in which an exon that encodes a different $5^{\prime}$-untranslated region begins transcripts that are spliced to a major peptide-encoding exon VIII. A number of features of the rodent $5^{\prime}$ flanking BDNF genomic sequences fall into 2 clusters, with cluster 2 covering $\sim 3$ $\mathrm{kb}$ of genomic sequence and providing the $5^{\prime}$ flanking regions for exons IV, V, and VI. BDNF containing exons IV and VIII (termed BDNF4) is expressed at high levels in the brain, including within neural circuits implicated in addiction [200].

Activational influences of gonadal hormones. The Bdnf gene promoter contains an ERE, and estradiol increases BDNF expression in the medial and basomedial amygdala and in CA1 and CA3 
regions of the hippocampus [204]. Stress and estradiol interact in the regulation of BDNF in females [205]. In this study, stress decreased BDNF in the prefrontal cortex in intact female rats, but not males or OVX females. Further, estradiol administration to stressed OVX females increased BDNF levels [205]. These results are consistent with previous research showing co-localization of ER and Bdnf in forebrain neurons [206, 207].

BDNF and TrkB receptors may play an important role in sex differences in plasticity of affective and motivational circuits that influence addictive behavior. For example, there are well documented sex differences in the stress response of mammals [52, 208-210], and stress can precipitate the initiation of drug taking and relapse in humans and animal models [44, 117, 211-213]. Therapies that promote reduction in stress axis activity may need to be modified according to gender/sex since many activities that reduce stress and enhance BDNF are likely to have different efficacies for males and females, as is true for the effects of exercise on cocaine selfadministration [205, 214, 215].

Organizational influences: gonadal hormones and sex chromosomes. The extent to which BDNF and TrkB receptors are influenced in a sex-specific way by factors during development has not been extensively investigated. In one experiment with the four core genotype mice, $X Y$ sex chromosome complement was found to be related to BDNF-related genes. Weanling mice with XY chromosomes had significantly lower TrkB expression in the basolateral amygdala compared to XX mice, but these differences did not persist into adulthood [216]. In this study it was also shown that mice exposed to testicular hormones during development exhibited lower BDNF in the amygdala compared to gonadectomized mice. Furthermore, neonatal exposure to masculinizing gonadal hormones results in sex-specific and region-specific effects on BDNF in the hippocampus early in development, suggesting that BDNF may play a role in sexual differentiation of the brain [217] in addition to a role in neurogenesis in the adult.

Organizational influences: autosomes. In a large human study aimed at identifying SNPs associated with vulnerability to polysubstance abuse, positive markers were found to flank the Bdnf gene [218]. Further analysis demonstrated that a dinucleotiderepeat polymorphism located close to the $5^{\prime}$ end of the $B d n f$ gene was also associated with drug abuse vulnerability. A common single-nucleotide polymorphism (G196A; rs6265) in Bdnf results in a valine (Val) to methionine (Met) substitution in the prodomain (Val66Met). This SNP has been shown to affect intracellular trafficking and activity-dependent secretion of BDNF, with $\mathrm{Val} / \mathrm{Val}$ allele carriers having increased BDNF secretion [219]. The 66Val allele of the Val66Met polymorphism is associated with vulnerability to methamphetamine and heroin dependence in Chinese men [220]. Interestingly, the 66Met allele is associated with increased risk for anxiety disorders [221], a result that seems at odds with the connection between the $66 \mathrm{Val}$ allele and addiction.

A mouse model was engineered in which the human Bdnf Val66Met SNP sequence was inserted into the Bdnf gene [222]. This study showed that the Met allele is associated with increased expression of anxiety-like and depressive-like behaviors in adult females. Furthermore, the anxiogenic effects of the $66 \mathrm{Met}$ allele are most apparent during the stage of the estrous cycle in which estrogen has just rapidly fallen. Although neither the human nor the mouse studies specifically compared males and females, the results are broadly consistent with the evolving hypothesis that women and girls are more likely to begin taking drugs as selfmedication to reduce stress or alleviate depression, whereas males are more likely to engage in risky behaviors that include experimenting with drugs of abuse [223].

Organizational influences: epigenetics. In a seminal study, Vassoler [224] showed that male, but not female, offspring of sires that self-administered cocaine for $60 \mathrm{~d}$ (the duration of rat spermatogenesis) prior to mating had delayed acquisition and reduced maintenance of cocaine self-administration, as well as reduced motivation to work for cocaine under a progressive ratio (PR) schedule of reinforcement. This was not a general reduction in motivated behavior or the ability to learn, as the male cocainesired offspring showed normal sucrose self-administration. Although this apparent "protective effect" of paternal cocaine exposure on male offspring seems to contrast with the common human scenario in which substance use disorders run in families, it fits with Barker's "developmental origins of health and disease" hypothesis that developmental programming in response to adverse environmental conditions prepares offspring for these conditions upon birth and during development [225].

The multigenerational effect of paternal cocaine selfadministration was due, in part, to an increase in BDNF transcript and protein in the medial prefrontal cortex in male, but not female, cocaine-sired rats [224]. The requirement for BDNF was demonstrated by reversal of diminished cocaine selfadministration in male cocaine-sired rats with administration of a TrkB receptor antagonist. The study demonstrated an increase in acetylation of histone $\mathrm{H} 3$ in the Bdnf promoter of exon IV in both the sperm of sires that self-administered cocaine as well as in the male offspring, indicating that voluntary paternal ingestion of cocaine results in epigenetic reprogramming of the germline, having profound effects on medial prefrontal cortex gene expression and resistance to cocaine reinforcement in male offspring. A subsequent study showed similar effects in male offspring of female mice who were injected with cocaine during pregnancy [226], although BDNF expression was only increased in the adult, but not juvenile (postnatal day 16) male frontal cortex.

An unanswered question is why parental cocaine exposure alters BDNF expression in male, but not female, offspring. Given that paternal cocaine exposure specifically increases acetylated histone $\mathrm{H} 3$ (H3K9K14ac2) within the Bdnf promoter in male offspring, a likely mechanism may be related to the finding that neonatal males (at least up to postnatal day 6) have greater H3K9K14Ac in the cortex and hippocampus compared to females [227]. This sex difference is testosterone-dependent, as treating newborn females with testosterone increased levels of H3K9K14AC to those observed in males. However; there are still significant gaps in knowledge, including how to explain that maternal cocaine exposure resulted in increased acetylation of histone $\mathrm{H} 3$ in male offspring only at postnatal day 60 [226] —clearly past the neonatal effects just discussed. One possibility that requires direct testing is that sex-dependent developmental changes in the methylation state of either the Bdnf promoter or ERa could increase or decrease the ability of $B d n f$ to be acetylated. In support of this, the rat Bdnf exon IV promoter contains eight $\mathrm{CpG}$ sites that serve as binding domains for methyl-CpG-binding protein 2 (MeCP2) [228]. In general, MeCP2 inhibits transcription through recruitment of histone deacetylases, co-repressors, and histone methyltransferases, all of which can act together to silence the $B d n f$ gene through chromatin remodeling $[228,229]$. As such, the level of Bdnf transcription can be increased via decreased MeCP2 expression or increased dissociation of MeCP2 from Bdnf promoter IV. Interestingly, it has been shown that males express significantly less MeCP2 than females in the developing amygdala and ventromedial hypothalamus at postnatal day 1 [230]. The sex differences in MeCP2 expression were transient, largely disappearing by postnatal day 10 . This raises the possibility that decreased MeCP2 expression in males provides a permissive environment for increased histone acetylation and BDNF expression. Consistent with this, maternal cocaine exposure results in decreased global DNA methylation in male pups at postnatal day 3 [129]. Two caveats of this study are that only male pups were used, and global DNA methylation was subsequently increased in older male offspring. 
BDNF expression can also be regulated by ERa. The Bdnf gene contains an estradiol response element (ERE) that is thought to be responsible for both testosterone (via aromatization to estradiol) and estradiol effects on BDNF expression [231]. However, the effects of gonadal hormones on BDNF expression are complex and appear to depend on the timing of hormonal exposure, developmental stage, and the specific brain region. High levels of estradiol receptor alpha $(E R a)$ protein expression are observed in the cortex and hippocampus at birth, but decline as animals approach puberty [232]. This decline in cortical ERa in the cortex may be due to progressive methylation of one of the six promoters of the mouse ERa gene beginning at postnatal day 10 in both male and female mice [233]. Taken together, these findings suggest that epigenetic marks onto the exon IV Bdnf promoter can pass through either maternal or paternal transmission and depend on the developmental stage of the offspring $[224,226]$.

Synthesis: how organizational and contingent factors can lead to sex differences in addiction

The NIH introduced new guidelines in 2016 for addressing sex as a biological variable (SABV) in NIH grant applications. Importantly, this is neither a mandate to include males and females in every study nor an attempt to force every lab to focus on sex differences. Rather, the discussion of SABV is now expected to be an aspect of rigor and reproducibility, and when both females and males are used, data are to be reported by sex, even when there are no differences. We hope that this review on known sex differences in mechanisms underlying reward and addiction will highlight two main points: 1 . males and females differ significantly in many behavioral and mechanistic aspects of the addiction cycle, and 2. there is more that we do NOT know than we do know in the field of addiction. The majority of studies to date that specifically address sex differences in addictive behavior have focused on activational effects of ovarian hormones using different drugs, doses, routes of administration, rodent species, and behavioral paradigms. In addition, many studies have reported sex differences in behavior but provided no mechanistic explanations. This is a critical start, but we are ready to advance the field. We think that the more recent understanding of fundamental knowledge on genetics, epigenetics, molecular biology, and transgenerational mechanisms of inheritance combined with the energized drive to conduct studies that do not assume females are simply males with an "fe" tacked on the front will enable full understanding of the how, why, and when males and females are different (or the same). Only then can addictive disorders be successfully prevented and treated in the entire population, which-at the last U.S. census count (2010)—was $50.8 \%$ female.

We have taken the approach of highlighting four neural systems that (1) are critically involved in the addiction cycle and (2) have identified sex differences in the context of addiction. These are: dopamine, MORs, KORs, and BDNF. This is by no means an exhaustive list, but we think the depth of mechanistic knowledge about these systems within our framework is important and discussing each system within the context of gonadal hormones, sex chromosomes, autosomes, and epigenetics helps frame what we do, and do not know, and more importantly, provides guidelines for filling in gaps in knowledge.

\section{FUTURE RESEARCH DIRECTIONS}

Incredible research is being conducted on fundamental mechanisms underlying how males and females develop into sexually dimorphic organisms, and how environmental exposure and experience map onto this dimorphism to produce a spectrum of behavioral outputs. Great strides have been made in the specific realms of development, sex (reproductive) behavior, stress reactivity, and multigenerational, sex-dependent inheritance. As this review makes clear, some strong studies have been conducted linking these fundamental mechanisms to higher order behaviors and pathophysiologies such as substance use disorder. However, much needs to be done.

In our view, some of the outstanding biological questions that emerged from the framework of this review are:

1. What are baseline sex similarities and differences in dopamine, MOR, KOR, and BDNF systems at each mechanistic level (e.g., molecular, neuroanatomical, functional, behavioral)?

2. How do dopamine, MOR, KOR, and BDNF systems respond during each stage of the addiction cycle in males and females? Is this drug-dependent? Is it dependent on gonadal hormones (organizational/activational)?

3. What mediates sex differences that arise from sex chromosome complement rather than gonadal hormones? What is the role of the placenta in mediating these effects?

4. Why are so many genes in the adult striatum differentially methylated in males and females? What are those genes, and are there sex differences in function?

5. Are there sex differences in efficacy of pharmacotherapy treatments (i.e., methadone, buprenorphine, naloxone) for opioid addiction?

Finally, how might current knowledge and answers to the above questions inform our approaches to prevention and treatment of addiction? First, we must painstakingly determine whether findings in laboratory animals (under tightly controlled conditions) translate to humans. Second, we must operate outside of our comfort zones to test sex-specific treatments. There is already substantial evidence that current treatment practices and psychotherapies are not ideal for both genders [25, 234]. We hope this review has highlighted where there are gaps in knowledge and will help to initiate new research into the mechanisms specifically mediating addiction in females and males.

\section{ACKNOWLEDGEMENTS}

The work discussed in this review was funded in part by grants from the $\mathrm{NIH}$ : DA033526 and DA023094 (Chartoff), and NIH DA039952 (Becker).

\section{ADDITIONAL INFORMATION}

Competing interests: The authors declare that they have no competing interests.

Publisher's note: Springer Nature remains neutral with regard to jurisdictional claims in published maps and institutional affiliations.

\section{REFERENCES}

1. Wagner FA, Anthony JC. From first drug use to drug dependence; developmental periods of risk for dependence upon marijuana, cocaine, and alcohol. Neuropsychopharmacology. 2002;26:479-88.

2. Wagner FA, Anthony JC. Male-female differences in the risk of progression from first use to dependence upon cannabis, cocaine, and alcohol. Drug Alcohol Depend. 2007;86:191-8.

3. NSDUH NSoDUaH. Substance Abuse and Mental Health Services Administration, Results from the 2013 National Survey on Drug Use and Health: Summary of National Findings, NSDUH Series H-48, HHS Publication No. (SMA) 14-4863. Rockville, MD: Substance Abuse and Mental Health Services Administration, 2014.

4. Cotto JH, Davis E, Dowling GJ, Elcano JC, Staton AB, Weiss SR. Gender effects on drug use, abuse, and dependence: a special analysis of results from the National Survey on Drug Use and Health. Gend Med. 2010;7:402-13.

5. McHugh RK, Votaw VR, Sugarman DE, Greenfield SF. Sex and gender differences in substance use disorders. Clin Psychol Rev. 2017 Nov 10. pii: S0272-7358(17) 30250-7. https://doi.org/10.1016/j.cpr.2017.10.012. [Epub ahead of print]. PMID: 29174306. 
6. Marsh JC, Park K, Lin YA, Bersamira C. Gender differences in trends for heroin use and nonmedical prescription opioid use, 2007-2014. J Subst Abus Treat. 2018;87:79-85

7. Brady JE, Giglio R, Keyes KM, DiMaggio C, Li G. Risk markers for fatal and nonfatal prescription drug overdose: a meta-analysis. Inj Epidemiol. 2017;4:24.

8. Cerda M, Ransome Y, Keyes KM, Koenen KC, Tracy M, Tardiff KJ, Vlahov D, Galea S. Prescription opioid mortality trends in New York City, 1990-2006: examining the emergence of an epidemic. Drug Alcohol Depend. 2013;132:53-62.

9. Kuntsche E, Muller S. Why do young people start drinking? Motives for first-time alcohol consumption and links to risky drinking in early adolescence. Eur Addict Res. 2012;18:34-9.

10. Muller $S$, Kuntsche E. Do the drinking motives of adolescents mediate the link between their parents' drinking habits and their own alcohol use? J Stud Alcohol Drugs. 2011;72:429-37.

11. Columbia University. National center on addiction and substance abuse. Women under the influence. xi Baltimore, MD: Johns Hopkins University Press; 2006. p. 292.

12. Vigna-Taglianti FD, Burroni $P$, Mathis $F$, Versino $E$, Beccaria $F$, Rotelli $M$, Garneri M, Picciolini A, Bargagli AM, Group VES. Gender differences in heroin addiction and treatment: results from the VEdeTTE cohort. Subst Use Misuse. 2016;51: 295-309.

13. Wilson HW, Widom CS. A prospective examination of the path from child abuse and neglect to illicit drug use in middle adulthood: the potential mediating role of four risk factors. J Youth Adolesc. 2009;38:340-54.

14. Haas AL, Peters RH. Development of substance abuse problems among drug involved offenders. Evid Telesc Eff J Subst Abus. 2000;12:241-53.

15. Koob GF, Volkow ND. Neurocircuitry of addiction. Neuropsychopharmacology. 2010;35:217-38.

16. Koob GF. Neurocircuitry of alcohol addiction: synthesis from animal models. Handb Clin Neurol. 2014;125:33-54.

17. Clarke TK, Krause K, Li T, Schumann G. An association of prodynorphin polymorphisms and opioid dependence in females in a Chinese population. Addict Biol. 2009;14:366-70.

18. Belin D, Everitt BJ. Cocaine seeking habits depend upon dopamine-dependent serial connectivity linking the ventral with the dorsal striatum. Neuron. 2008;57:432-41.

19. Kalivas PW, Volkow ND. The neural basis of addiction: a pathology of motivation and choice. Am J Psychiatry. 2005;162:1403-13.

20. Nestler EJ. Is there a common molecular pathway for addiction? Nat Neurosci. 2005;8:1445-9.

21. Wise RA, Koob GF. The development and maintenance of drug addiction. Neuropsychopharmacology. 2014;39:254-62.

22. Chartoff EH, Carlezon WA Jr.. Drug withdrawal conceptualized as a stressor. Behav Pharmacol. 2014;25:473-92.

23. Everitt BJ, Robbins TW. Neural systems of reinforcement for drug addiction: from actions to habits to compulsion. Nat Neurosci. 2005:8:1481-9.

24. Westermeyer J, Boedicker AE. Course, severity, and treatment of substance abuse among women versus men. Am J Drug Alcohol Abus. 2000;26:523-35.

25. Greenfield SF, Back SE, Lawson K, Brady KT. Substance abuse in women. Psychiatr Clin North Am. 2010;33:339-55.

26. Becker JB, Koob GF. Sex differences in animal models: focus on addiction. Pharmacol Rev. 2016;68:242-63.

27. Barker JM, Taylor JR. Sex differences in incentive motivation and the relationship to the development and maintenance of alcohol use disorders. Physiol Behav. 2017. https://doi.org/10.1016/j.physbeh.2017.09.027

28. Carroll ME, Lynch WJ. How to study sex differences in addiction using animal models. Addict Biol. 2016;21:1007-29.

29. Mavrikaki M, Pravetoni M, Page S, Potter D, Chartoff E. Oxycodone selfadministration in male and female rats. Psychopharmacology. 2017;234:977-87.

30. Sesack SR, Grace AA. Cortico-Basal Ganglia reward network: microcircuitry. Neuropsychopharmacology. 2010;35:27-47.

31. Wise RA. The brain and reward. In: Liebman JM, Cooper SJ, editors. The neuropharmacological basis of reward. Oxford, UK: Clarendon; 1989. p. 377-424.

32. Johnson SW, North RA. Opioids excite dopamine neurons by hyperpolarization of local interneurons. J Neurosci. 1992;12:483-8.

33. Jalabert M, Bourdy R, Courtin J, Veinante P, Manzoni OJ, Barrot M, Georges F. Neuronal circuits underlying acute morphine action on dopamine neurons. Proc Natl Acad Sci USA 2011;108:16446-50.

34. Schultz W, Carelli RM, Wightman RM. Phasic dopamine signals: from subjective reward value to formal economic utility. Curr Opin Behav Sci. 2015;5:147-54.

35. Wise RA. Dopamine, learning and motivation. Nat Rev Neurosci. 2004;5:483-94

36. Wheeler RA, Carelli RM. Dissecting motivational circuitry to understand substance abuse. Neuropharmacology. 2009;56:149-59.

37. Kalivas PW, Lalumiere RT, Knackstedt L, Shen H. Glutamate transmission in addiction. Neuropharmacology. 2009;56:169-73.
38. Bruchas MR, Land BB, Chavkin C. The dynorphin/kappa opioid system as a modulator of stress-induced and pro-addictive behaviors. Brain Res. 2010; 1314:44-55.

39. Graham DL, Edwards S, Bachtell RK, DiLeone RJ, Rios M, Self DW. Dynamic BDNF activity in nucleus accumbens with cocaine use increases self-administration and relapse. Nat Neurosci. 2007;10:1029-37.

40. Ahmed SH, Koob GF. Transition from moderate to excessive drug intake: change in hedonic set point. Science. 1998;282:298-300.

41. Koob GF, Le Moal M. Addiction and the brain antireward system. Annu Rev Psychol. 2008;59:29-53.

42. Chartoff EH, Papadopoulou M, MacDonald ML, Parsegian A, Potter D, Konradi C, Carlezon WA Jr.. Desipramine reduces stress-activated dynorphin expression and CREB phosphorylation in NAc tissue. Mol Pharmacol. 2009;75:704-12.

43. Goldstein RZ, Volkow ND. Dysfunction of the prefrontal cortex in addiction: neuroimaging findings and clinical implications. Nat Rev Neurosci. 2011;12:652-69.

44. Potenza MN, Hong KI, Lacadie CM, Fulbright RK, Tuit KL, Sinha R. Neural correlates of stress-induced and cue-induced drug craving: influences of sex and cocaine dependence. Am J Psychiatry. 2012;169:406-14.

45. Venniro M, Caprioli D, Shaham Y. Animal models of drug relapse and craving: From drug priming-induced reinstatement to incubation of craving after voluntary abstinence. Prog Brain Res. 2016;224:25-52.

46. Beardsley PM, Howard JL, Shelton KL, Carroll FI. Differential effects of the novel kappa opioid receptor antagonist, JDTic, on reinstatement of cocaine-seeking induced by footshock stressors vs cocaine primes and its antidepressant-like effects in rats. Psychopharmacology. 2005;183:118-26.

47. Pickens $\mathrm{CL}$, Airavaara $\mathrm{M}$, Theberge $\mathrm{F}$, Fanous $\mathrm{S}$, Hope BT, Shaham Y. Neurobiology of the incubation of drug craving. Trends Neurosci. 2011;34:411-20.

48. Schlosburg JE, Whitfield TW Jr, Park PE, Crawford EF, George O, Vendruscolo LF, Koob GF. Long-term antagonism of kappa opioid receptors prevents escalation of and increased motivation for heroin intake. J Neurosci. 2013;33:19384-92.

49. McCarthy MM, Multifaceted origins of sex differences in the brain. Philos Trans $R$ Soc Lond B Biol Sci.2016;371:20150106

50. Sanchis-Segura CS, Becker JB. Why we should consider sex (and study sex differences) in addiction research. Addict Biol. 2016;21:995-1006.

51. de Vries GJ, Forger NG. Sex differences in the brain: a whole body perspective. Biol Sex Differ. 2015;6:15.

52. Bale TL, Epperson CN. Sex differences and stress across the lifespan. Nat Neurosci. $2015 ; 18: 1413-20$

53. Nugent BM, Bale TL. The omniscient placenta: Metabolic and epigenetic regulation of fetal programming. Front Neuroendocrinol. 2015;39:28-37.

54. Gregg C, Zhang J, Butler JE, Haig D, Dulac C. Sex-specific parent-of-origin allelic expression in the mouse brain. Science. 2010;329:682-5.

55. Arnold AP, Chen X. What does the "four core genotypes" mouse model tell us about sex differences in the brain and other tissues? Front Neuroendocrinol. 2009;30:1-9.

56. Egervari G, Ciccocioppo R, Jentsch JD, Hurd YL. Shaping vulnerability to addiction - the contribution of behavior, neural circuits and molecular mechanisms. Neurosci Biobehav Rev. 2018;85:117-25.

57. Goldman D, Oroszi G, Ducci F. The genetics of addictions: uncovering the genes. Nat Rev Genet. 2005;6:521-32.

58. Bonthuis PJ, Huang WC, Stacher Horndli CN, Ferris E, Cheng T, Gregg C. Noncanonical genomic imprinting effects in offspring. Cell Rep. 2015;12:979-91.

59. Gregg C, Zhang J, Weissbourd B, Luo S, Schroth GP, Haig D, Dulac C. Highresolution analysis of parent-of-origin allelic expression in the mouse brain. Science. 2010;329:643-8.

60. Tsankova N, Renthal W, Kumar A, Nestler EJ. Epigenetic regulation in psychiatric disorders. Nat Rev Neurosci. 2007;8:355-67.

61. Vassoler FM, Sadri-Vakili G. Mechanisms of transgenerational inheritance of addictive-like behaviors. Neuroscience. 2014;264:198-206.

62. Sha K. A mechanistic view of genomic imprinting. Annu Rev Genom Hum Genet. 2008;9:197-216

63. Skinner MK. Role of epigenetics in developmental biology and transgenerational inheritance. Birth Defects Res C Embryo Today. 2011;93:51-5.

64. McCarthy MM, Nugent BM. At the frontier of epigenetics of brain sex differences. Front Behav Neurosci. 2015;9:221.

65. Kouzarides T. Chromatin modifications and their function. Cell. 2007;128: 693-705.

66. Lugli G, Torvik VI, Larson J, Smalheiser NR. Expression of microRNAs and their precursors in synaptic fractions of adult mouse forebrain. J Neurochem. 2008;106:650-61.

67. Smith ACW, Kenny PJ. MicroRNAs regulate synaptic plasticity underlying drug addiction. Genes Brain Behav. 2018;17(3):e12424. https://doi.org/10.1111/ gbb.12424. Epub 2017 Oct 10. PMID: 28873276.

68. Friedman RC, Farh KK, Burge CB, Bartel DP. Most mammalian mRNAs are conserved targets of microRNAs. Genome Res. 2009;19:92-105. 
69. Leung AKL. The whereabouts of microRNA Actions: cytoplasm and beyond. Trends Cell Biol. 2015;25:601-10.

70. Bohacek J, Mansuy IM. Epigenetic inheritance of disease and disease risk. Neuropsychopharmacology. 2013;38:220-36.

71. Morgan CP, Bale TL. Sex differences in microRNA regulation of gene expression: no smoke, just miRs. Biol Sex Differ. 2012;3:22.

72. Jonkman S, Kenny PJ. Molecular, cellular, and structural mechanisms of cocaine addiction: a key role for microRNAs. Neuropsychopharmacology. 2013;38: 198-211.

73. Nestler EJ. Epigenetic mechanisms of drug addiction. Neuropharmacology. 2014:76 Pt B:259-68.

74. Robison AJ, Nestler EJ. Transcriptional and epigenetic mechanisms of addiction. Nat Rev Neurosci. 2011;12:623-37.

75. Heyer MP, Kenny PJ. Corticostriatal microRNAs in addiction. Brain Res. 2015;1628:2-16.

76. Cedar $\mathrm{H}$, Bergman Y. Linking DNA methylation and histone modification: patterns and paradigms. Nat Rev Genet. 2009;10:295-304.

77. Wang S, Wu W, Claret FX. Mutual regulation of microRNAs and DNA methylation in human cancers. Epigenetics. 2017;12:187-97.

78. Guil S, Esteller M. DNA methylomes, histone codes and miRNAs: tying it all together. Int J Biochem Cell Biol. 2009;41:87-95.

79. Ghahramani NM, Ngun TC, Chen PY, Tian Y, Krishnan S, Muir S, Rubbi L, Arnold AP, de Vries GJ, Forger NG, Pellegrini M, Vilain E. The effects of perinatal testosterone exposure on the DNA methylome of the mouse brain are lateemerging. Biol Sex Differ. 2014;5:8.

80. Yohn NL, Bartolomei MS, Blendy JA. Multigenerational and transgenerational inheritance of drug exposure: the effects of alcohol, opiates, cocaine, marijuana, and nicotine. Prog Biophys Mol Biol. 2015;118:21-33.

81. Skinner MK. Environmental epigenetic transgenerational inheritance and somatic epigenetic mitotic stability. Epigenetics. 2011;6:838-42.

82. Stoof JC, Kebabian JW. Two dopamine receptors: biochemistry, physiology and pharmacology. Life Sci. 1984;35:2281-96.

83. Andersen SL, Rutstein M, Benzo JM, Hostetter JC, Teicher MH. Sex differences in dopamine receptor overproduction and elimination. Neuroreport. 1997;8:1495-8.

84. Andersen SL, Teicher MH. Sex differences in dopamine receptors and their relevance to ADHD. Neurosci Biobehav Rev. 2000;24:137-41.

85. Teicher MH, Krenzel E, Thompson AP, Andersen SL. Dopamine receptor pruning during the peripubertal period is not attenuated by NMDA receptor antagonism in rat. Neurosci Lett. 2003;339:169-71.

86. Kopec AM, Smith CJ, Ayre NR, Sweat SC, Bilbo SD. Microglial elimination of dopamine D1 receptors defines sex-specific changes in nucleus accumbens development and social play behavior during adolescence. bioRXiv. 2017. https://doi.org/10.1101/211029

87. Becker JB, Ramirez VD. Experimental studies on the development of sex differences in the release of dopamine from striatal tissue fragments in vitro. Neuroendocrinology. 1981:32:168-73.

88. Becker JB, Ramirez VD. Sex differences in the amphetamine stimulated release of catecholamines from rat striatal tissue in vitro. Brain Res. 1981;204:361-72.

89. Perry AN, Westenbroek C, Becker JB. Impact of pubertal and adult estradiol treatments on cocaine self-administration. Horm Behav. 2013;64:573-8.

90. Mermelstein PG. Membrane-localised oestrogen receptor alpha and beta influence neuronal activity through activation of metabotropic glutamate receptors. J Neuroendocrinol. 2009;21:257-62.

91. Mermelstein PG, Becker JB, Surmeier DJ. Estradiol reduces calcium currents in rat neostriatal neurons via a membrane receptor. J Neurosci. 1996;16:595-604.

92. Schultz KN, von Esenwein SA, Hu M, Bennett AL, Kennedy RT, Musatov S, ToranAllerand $C D$, Kaplitt MG, Young LJ, Becker JB. Viral vector-mediated overexpression of estrogen receptor-alpha in striatum enhances the estradiolinduced motor activity in female rats and estradiol-modulated GABA release. J Neurosci. 2009;29:1897-903.

93. Grove-Strawser D, Boulware MI, Mermelstein PG. Membrane estrogen receptors activate the metabotropic glutamate receptors mGluR5 and mGluR3 to bidirectionally regulate CREB phosphorylation in female rat striatal neurons. Neuroscience. 2010;170:1045-55.

94. Meitzen J, Mermelstein PG. Estrogen receptors stimulate brain region specific metabotropic glutamate receptors to rapidly initiate signal transduction pathways. J Chem Neuroanat. 2011;42:236-41.

95. Boulware MI, Kordasiewicz H, Mermelstein PG. Caveolin proteins are essential for distinct effects of membrane estrogen receptors in neurons. J Neurosci. 2007:27:9941-50.

96. Kritzer MF, Creutz LM. Region and sex differences in constituent dopamine neurons and immunoreactivity for intracellular estrogen and androgen receptors in mesocortical projections in rats. J Neurosci. 2008;28:9525-35.

97. Xiao L, Becker JB. Effects of estrogen agonists on amphetamine-stimulated striatal dopamine release. Synapse. 1998:29:379-91.
98. Cummings JA, Jagannathan L, Jackson LR, Becker JB. Sex differences in the effects of estradiol in the nucleus accumbens and striatum on the response to cocaine: neurochemistry and behavior. Drug Alcohol Depend. 2014;135:22-8.

99. Becker JB. Direct effect of 17 beta-estradiol on striatum: sex differences in dopamine release. Synapse. 1990;5:157-64.

100. Shams WM, Cossette MP, Shizgal P, Brake WG. 17beta-estradiol locally increases phasic dopamine release in the dorsal striatum. Neurosci Lett. 2018;665:29-32.

101. Shams WM, Sanio C, Quinlan MG, Brake WG. 17beta-Estradiol infusions into the dorsal striatum rapidly increase dorsal striatal dopamine release in vivo. Neuroscience. 2016;330:162-70.

102. Castner SA, Xiao L, Becker JB. Sex differences in striatal dopamine: in vivo microdialysis and behavioral studies. Brain Res. 1993;610:127-34.

103. Walker QD, Rooney MB, Wightman RM, Kuhn CM. Dopamine release and uptake are greater in female than male rat striatum as measured by fast cyclic voltammetry. Neuroscience. 2000;95:1061-70.

104. Orendain-Jaime EN, Ortega-lbarra JM, Lopez-Perez SJ. Evidence of sexual dimorphism in D1 and D2 dopaminergic receptors expression in frontal cortex and striatum of young rats. Neurochem Int. 2016;100:62-66.

105. Bazzett TJ, Becker JB. Sex differences in the rapid and acute effects of estrogen on striatal D2 dopamine receptor binding. Brain Res. 1994;637:163-72.

106. Levesque D, Gagnon S, Di Paolo T. Striatal D1 dopamine receptor density fluctuates during the rat estrous cycle. Neurosci Lett. 1989;98:345-50.

107. Yoest KE, Cummings JA, Becker JB. Estradiol, dopamine and motivation. Cent Nerv Syst Agents Med Chem. 2014;14:83-89.

108. Lynch WJ, Roth ME, Mickelberg JL, Carroll ME. Role of estrogen in the acquisition of intravenously self-administered cocaine in female rats. Pharmacol Biochem Behav. 2001;68:641-6.

109. Becker JB, Hu M. Sex differences in drug abuse. Front Neuroendocrinol. 2008;29:36-47.

110. Swalve N, Smethells JR, Zlebnik NE, Carroll ME. Sex differences in reinstatement of cocaine-seeking with combination treatments of progesterone and atomoxetine. Pharmacol Biochem Behav. 2016;145:17-23.

111. Yang $\mathrm{H}$, Zhao W, Hu M, Becker JB. Interactions among ovarian hormones and time of testing on behavioral sensitization and cocaine self-administration. Behav Brain Res. 2007;184:174-84.

112. Hu M, Crombag HS, Robinson TE, Becker JB. Biological basis of sex differences in the propensity to self-administer cocaine. Neuropsychopharmacology. 2004; 29:81-5.

113. Jackson LR, Robinson TE, Becker JB. Sex differences and hormonal influences on acquisition of cocaine self-administration in rats. Neuropsychopharmacology. 2006;31:129-38.

114. Perry AN, Westenbroek C, Becker JB. The development of a preference for cocaine over food identifies individual rats with addiction-like behaviors. PLoS ONE. 2013;8:e79465.

115. Perry AN, Westenbroek C, Jagannathan L, Becker JB. The roles of dopamine and alpha1-adrenergic receptors in cocaine preferences in female and male rats. Neuropsychopharmacology. 2015;40:2696-704.

116. Caine SB, Bowen CA, Yu G, Zuzga D, Negus SS, Mello NK. Effect of gonadectomy and gonadal hormone replacement on cocaine self-administration in female and male rats. Neuropsychopharmacology. 2004;29:929-42.

117. Sinha R, Fox $H$, Hong Kl, Sofuoglu M, Morgan PT, Bergquist KT. Sex steroid hormones, stress response, and drug craving in cocaine-dependent women: implications for relapse susceptibility. Exp Clin Psychopharmacol. 2007;15:445-52.

118. Calipari ES, Juarez B, Morel C, Walker DM, Cahill ME, Ribeiro E, Roman-Ortiz C, Ramakrishnan C, Deisseroth K, Han MH, Nestler EJ. Dopaminergic dynamics underlying sex-specific cocaine reward. Nat Commun. 2017;8:13877.

119. Carruth LL, Reisert I, Arnold AP. Sex chromosome genes directly affect brain sexual differentiation. Nat Neurosci. 2002;5:933-4.

120. Dewing $P$, Chiang CW, Sinchak K, Sim H, Fernagut PO, Kelly S, Chesselet MF, Micevych PE, Albrecht KH, Harley VR, Vilain E. Direct regulation of adult brain function by the male-specific factor SRY. Curr Biol. 2006;16:415-20.

121. Czech DP, Lee J, Sim H, Parish CL, Vilain E, Harley VR. The human testisdetermining factor SRY localizes in midbrain dopamine neurons and regulates multiple components of catecholamine synthesis and metabolism. J Neurochem. 2012;122:260-71.

122. Jeong H, Kim MS, Kwon J, Kim KS, Seol W. Regulation of the transcriptional activity of the tyrosine hydroxylase gene by androgen receptor. Neurosci Lett. 2006;396:57-61.

123. Kritzer MF. Selective colocalization of immunoreactivity for intracellular gonadal hormone receptors and tyrosine hydroxylase in the ventral tegmental area, substantia nigra, and retrorubral fields in the rat. J Comp Neurol. 1997;379: 247-60.

124. Creutz LM, Kritzer MF. Estrogen receptor-beta immunoreactivity in the midbrain of adult rats: regional, subregional, and cellular localization in the A10, A9, and A8 dopamine cell groups. J Comp Neurol. 2002;446:288-300. 
125. Serova LI, Maharjan S, Huang A, Sun D, Kaley G, Sabban EL. Response of tyrosine hydroxylase and GTP cyclohydrolase I gene expression to estrogen in brain catecholaminergic regions varies with mode of administration. Brain Res. 2004;1015:1-8.

126. Quinn JJ, Hitchcott PK, Umeda EA, Arnold AP, Taylor JR. Sex chromosome complement regulates habit formation. Nat Neurosci. 2007;10:1398-400.

127. Barker JM, Torregrossa MM, Arnold AP, Taylor JR. Dissociation of genetic and hormonal influences on sex differences in alcoholism-related behaviors. J Neurosci. 2010;30:9140-4.

128. Pena CJ, Neugut YD, Calarco CA, Champagne FA. Effects of maternal care on the development of midbrain dopamine pathways and reward-directed behavior in female offspring. Eur J Neurosci. 2014;39:946-56.

129. Novikova SI, He F, Bai J, Cutrufello NJ, Lidow MS, Undieh AS. Maternal cocaine administration in mice alters DNA methylation and gene expression in hippocampal neurons of neonatal and prepubertal offspring. PLoS ONE. 2008;3:e1919.

130. Allen JW, Bennett DS, Carmody DP, Wang Y, Lewis M. Adolescent risk-taking as a function of prenatal cocaine exposure and biological sex. Neurotoxicol Teratol. 2014;41:65-70

131. Dow-Edwards D, lijima M, Stephenson S, Jackson A, Weedon J. The effects of prenatal cocaine, post-weaning housing and sex on conditioned place preference in adolescent rats. Psychopharmacology. 2014;231:1543-55.

132. Salas-Ramirez KY, Frankfurt M, Alexander A, Luine VN, Friedman E. Prenatal cocaine exposure increases anxiety, impairs cognitive function and increases dendritic spine density in adult rats: influence of sex. Neuroscience. 2010; 169:1287-95.

133. Dow-Edwards D. Sex differences in the effects of cocaine abuse across the life span. Physiol Behav. 2010;100:208-15.

134. Williams SK, Lauder JM, Johns JM. Prenatal cocaine disrupts serotonin signalingdependent behaviors: implications for sex differences, early stress and prenatal SSRI exposure. Curr Neuropharmacol. 2011;9:478-511.

135. He F, Lidow IA, Lidow MS. Consequences of paternal cocaine exposure in mice. Neurotoxicol Teratol. 2006;28:198-209.

136. Vassoler FM, Byrnes EM, Pierce RC. The impact of exposure to addictive drugs on future generations: physiological and behavioral effects. Neuropharmacology. 2014;76 Pt B:269-75.

137. Vassoler FM, Oliver DJ, Wyse C, Blau A, Shtutman M, Turner JR, Byrnes EM. Transgenerational attenuation of opioid self-administration as a consequence of adolescent morphine exposure. Neuropharmacology. 2017;113:271-80.

138. Levran O, Yuferov V, Kreek MJ. The genetics of the opioid system and specific drug addictions. Hum Genet. 2012;131:823-42.

139. Morley-Fletcher S, Palanza P, Parolaro D, Vigano D, Laviola G. Intrauterine position has long-term influence on brain mu-opioid receptor density and behaviour in mice. Psychoneuroendocrinology. 2003;28:386-400.

140. Lacy RT, Strickland JC, Feinstein MA, Robinson AM, Smith MA. The effects of sex estrous cycle, and social contact on cocaine and heroin self-administration in rats. Psychopharmacology. 2016;233:3201-10.

141. Lynch WJ, Carroll ME. Sex differences in the acquisition of intravenously selfadministered cocaine and heroin in rats. Psychopharmacology. 1999;144:77-82.

142. Carroll ME, Morgan AD, Lynch WJ, Campbell UC, Dess NK. Intravenous cocaine and heroin self-administration in rats selectively bred for differential saccharin intake: phenotype and sex differences. Psychopharmacology. 2002;161:304-13.

143. Roth ME, Casimir AG, Carroll ME. Influence of estrogen in the acquisition of intravenously self-administered heroin in female rats. Pharmacol Biochem Behav. 2002;72:313-8.

144. Gioiosa L, Chen X, Watkins R, Klanfer N, Bryant CD, Evans CJ, Arnold AP. Sex chromosome complement affects nociception in tests of acute and chronic exposure to morphine in mice. Horm Behav. 2008;53:124-30.

145. Haerian BS, Haerian MS. OPRM1 rs1799971 polymorphism and opioid dependence: evidence from a meta-analysis. Pharmacogenomics. 2013;14:813-24.

146. Mague SD, Isiegas C, Huang $P$, Liu-Chen LY, Lerman C, Blendy JA. Mouse model of OPRM1 (A118G) polymorphism has sex-specific effects on drug-mediated behavior. Proc Natl Acad Sci USA. 2009;106:10847-52.

147. Wang YJ, Huang P, Blendy JA, Liu-Chen LY. Brain region- and sex-specific alterations in DAMGO-stimulated [(35) S]GTPgammaS binding in mice with Oprm1 A112G. Addict Biol. 2014;19:354-61.

148. Loyd DR, Wang X, Murphy AZ. Sex differences in micro-opioid receptor expression in the rat midbrain periaqueductal gray are essential for eliciting sex differences in morphine analgesia. J Neurosci. 2008;28:14007-17.

149. Hwang CK, Song KY, Kim CS, Choi HS, Guo XH, Law PY, Wei LN, Loh HH. Epigenetic programming of mu-opioid receptor gene in mouse brain is regulated by MeCP2 and Brg1 chromatin remodelling factor. J Cell Mol Med. 2009; 13:3591-15.

150. Zhang Y, Picetti R, Butelman ER, Ho A, Blendy JA, Kreek MJ. Mouse model of the OPRM1 (A118G) polymorphism: differential heroin self-administration behavior compared with wild-type mice. Neuropsychopharmacology. 2015;40:1091-100.
151. Vassoler FM, Johnson-Collins NL, Carini LM, Byrnes EM. Next generation effects of female adolescent morphine exposure: sex-specific alterations in response to acute morphine emerge before puberty. Behav Pharmacol. 2014;25:173-81.

152. Vassoler FM, Wright SJ, Byrnes EM. Exposure to opiates in female adolescents alters mu opiate receptor expression and increases the rewarding effects of morphine in future offspring. Neuropharmacology. 2016;103:112-21.

153. Byrnes EM. Transgenerational consequences of adolescent morphine exposure in female rats: effects on anxiety-like behaviors and morphine sensitization in adult offspring. Psychopharmacology. 2005;182:537-44.

154. Byrnes JJ, Babb JA, Scanlan VF, Byrnes EM. Adolescent opioid exposure in female rats: transgenerational effects on morphine analgesia and anxiety-like behavior in adult offspring. Behav Brain Res. 2011;218:200-5.

155. Byrnes JJ, Johnson NL, Carini LM, Byrnes EM. Multigenerational effects of adolescent morphine exposure on dopamine D2 receptor function. Psychopharmacology. 2013;227:263-72.

156. Li CQ, Luo YW, Bi FF, Cui TT, Song L, Cao WY, Zhang JY, Li F, Xu JM, Hao W, Xing XW, Zhou FH, Zhou XF, Dai RP. Development of anxiety-like behavior via hippocampal IGF-2 signaling in the offspring of parental morphine exposure: effect of enriched environment. Neuropsychopharmacology. 2014;39:2777-87.

157. Cicero TJ, Adams ML, Giordano A, Miller BT, O'Connor L, Nock B. Influence of morphine exposure during adolescence on the sexual maturation of male rats and the development of their offspring. J Pharmacol Exp Ther. 1991;256: 1086-93.

158. Cicero TJ, Nock B, O'Connor L, Adams M, Meyer ER. Adverse effects of paternal opiate exposure on offspring development and sensitivity to morphine-induced analgesia. J Pharmacol Exp Ther. 1995;273:386-92.

159. Chavkin C, James IF, Goldstein A. Dynorphin is a specific endogenous ligand of the kappa opioid receptor. Science. 1982;215:413-5.

160. Mansour A, Fox CA, Akil H, Watson SJ. Opioid-receptor mRNA expression in the rat CNS: anatomical and functional implications. Trends Neurosci. 1995;18:2229.

161. Mansour A, Fox CA, Burke S, Akil H, Watson SJ. Immunohistochemical localization of the cloned mu opioid receptor in the rat CNS. J Chem Neuroanat. 1995;8:283-305.

162. Knoll AT, Carlezon WA Jr. Dynorphin, stress, and depression. Brain Res. 2010;1314:56-73.

163. Margolis EB, Hjelmstad GO, Bonci A, Fields HL. Kappa-opioid agonists directly inhibit midbrain dopaminergic neurons. J Neurosci. 2003;23:9981-6.

164. Margolis EB, Lock H, Chefer VI, Shippenberg TS, Hjelmstad GO, Fields HL. Kappa opioids selectively control dopaminergic neurons projecting to the prefrontal cortex. Proc Natl Acad Sci USA 2006;103:2938-42.

165. Ebner SR, Roitman MF, Potter DN, Rachlin AB, Chartoff EH. Depressive-like effects of the kappa opioid receptor agonist salvinorin $A$ are associated with decreased phasic dopamine release in the nucleus accumbens. Psychopharmacology. 2010;210:241-52.

166. Svingos AL, Colago EE, Pickel VM. Cellular sites for dynorphin activation of kappa-opioid receptors in the rat nucleus accumbens shell. J Neurosci. 1999;19:1804-13.

167. Cole RL, Konradi C, Douglass J, Hyman SE. Neuronal adaptation to amphetamine and dopamine: molecular mechanisms of prodynorphin gene regulation in rat striatum. Neuron. 1995;14:813-23.

168. Douglass J, McMurray CT, Garrett JE, Adelman JP, Calavetta L. Characterization of the rat prodynorphin gene. Mol Endocrinol. 1989;3:2070-8.

169. Knoll AT, Muschamp JW, Sillivan SE, Ferguson D, Dietz DM, Meloni EG, Carroll FI, Nestler EJ, Konradi C, Carlezon WA, Jr. Kappa opioid receptor signaling in the basolateral amygdala regulates conditioned fear and anxiety in rats. Biol Psychiatry. 2011;70:425-33.

170. Todtenkopf MS, Marcus JF, Portoghese PS, Carlezon WA Jr.. Effects of kappaopioid receptor ligands on intracranial self-stimulation in rats. Psychopharmacology. 2004;172:463-70.

171. Land BB, Bruchas MR, Lemos JC, Xu M, Melief EJ, Chavkin C. The dysphoric component of stress is encoded by activation of the dynorphin \{kappa\}-opioid system. J Neurosci. 2008;28:407-14.

172. McLaughlin JP, Land BB, Li S, Pintar JE, Chavkin C. Prior activation of kappa opioid receptors by $\mathrm{U} 50,488$ mimics repeated forced swim stress to potentiate cocaine place preference conditioning. Neuropsychopharmacology. 2006; 31:787-94.

173. Negus SS, Mello NK. Effects of chronic methadone treatment on cocaine- and food-maintained responding under second-order, progressive-ratio and concurrent-choice schedules in rhesus monkeys. Drug Alcohol Depend. 2004;74:297-309.

174. Redila V, Chavkin C. Stress-induced reinstatement of cocaine seeking is mediated by the kappa opioid system. Psychopharmacology. 2008;200:59-70.

175. Schindler AG, Li S, Chavkin C. Behavioral stress may increase the rewarding valence of cocaine-associated cues through a dynorphin/kappa-opioid 
receptor-mediated mechanism without affecting associative learning or memory retrieval mechanisms. Neuropsychopharmacology. 2010;35:1932-42.

176. Knoll AT, Meloni EG, Thomas JB, Carroll FI, Carlezon WA Jr.. Anxiolytic-like effects of kappa-opioid receptor antagonists in models of unlearned and learned fear in rats. J Pharmacol Exp Ther. 2007;323:838-45.

177. Mague SD, Pliakas AM, Todtenkopf MS, Tomasiewicz HC, Zhang Y, Stevens WC Jr., Jones RM, Portoghese PS, Carlezon WA Jr.. Antidepressant-like effects of kappa-opioid receptor antagonists in the forced swim test in rats. J Pharmacol Exp Ther. 2003;305:323-30.

178. Newton SS, Thome J, Wallace TL, Shirayama Y, Schlesinger L, Sakai N, Chen J, Neve R, Nestler EJ, Duman RS. Inhibition of cAMP response element-binding protein or dynorphin in the nucleus accumbens produces an antidepressant-like effect. J Neurosci. 2002;22:10883-90.

179. Chartoff E, Sawyer A, Rachlin A, Potter D, Pliakas A, Carlezon WA. Blockade of kappa opioid receptors attenuates the development of depressive-like behaviors induced by cocaine withdrawal in rats. Neuropharmacology. 2012;62:167-76.

180. Walker BM, Koob GF. Pharmacological evidence for a motivational role of [kappa]-opioid systems in ethanol dependence. Neuropsychopharmacology. 2007;33:643-52.

181. Carey AN, Borozny K, Aldrich JV, McLaughlin JP. Reinstatement of cocaine placeconditioning prevented by the peptide kappa-opioid receptor antagonist arodyn. Eur J Pharmacol. 2007;569:84-89.

182. Pfeiffer A, Brantl V, Herz A, Emrich HM. Psychotomimesis mediated by kappa opiate receptors. Science. 1986;233:774-6.

183. Russell SE, Rachlin AB, Smith KL, Muschamp J, Berry L, Zhao Z, Chartoff EH. Sex differences in sensitivity to the depressive-like effects of the kappa opioid receptor agonist U-50488 in rats. Biol Psychiatry. 2014;76:213-22.

184. Chartoff EH, Mavrikaki M. Sex differences in kappa opioid receptor function and their potential impact on addiction. Front Neurosci. 2015;9:466.

185. Mogil JS, Sternberg WF, Kest B, Marek P, Liebeskind JC. Sex differences in the antagonism of swim stress-induced analgesia: effects of gonadectomy and estrogen replacement. Pain. 1993;53:17-25.

186. Rasakham K, Liu-Chen LY. Sex differences in kappa opioid pharmacology. Life Sci. 2011;88:2-16

187. Forman LJ, Tingle V, Estilow S, Cater J. The response to analgesia testing is affected by gonadal steroids in the rat. Life Sci. 1989;45:447-54.

188. Klinge $\mathrm{CM}$, Jernigan SC, Mattingly $\mathrm{KA}$, Risinger $\mathrm{KE}$, Zhang J. Estrogen response element-dependent regulation of transcriptional activation of estrogen receptors alpha and beta by coactivators and corepressors. J Mol Endocrinol. 2004;33:387-410.

189. Gottsch ML, Navarro VM, Zhao Z, Glidewell-Kenney C, Weiss J, Jameson JL, Clifton DK, Levine JE, Steiner RA. Regulation of Kiss1 and dynorphin gene expression in the murine brain by classical and nonclassical estrogen receptor pathways. J Neurosci. 2009;29:9390-5.

190. Gruber CJ, Gruber DM, Gruber IM, Wieser F, Huber JC. Anatomy of the estrogen response element. Trends Endocrinol Metab. 2004;15:73-8.

191. Scott CJ, Clarke IJ, Tilbrook AJ. The effect of testosterone and season on prodynorphin messenger RNA expression in the preoptic area-hypothalamus of the ram. Domest Anim Endocrinol. 2008:34:440-50.

192. Douglass J, McKinzie AA, Pollock KM. Identification of multiple DNA elements regulating basal and protein kinase A-induced transcriptional expression of the rat prodynorphin gene. Mol Endocrinol. 1994;8:333-44.

193. Gu G, Rojo AA, Zee MC, Yu J, Simerly RB. Hormonal regulation of CREB phosphorylation in the anteroventral periventricular nucleus. J Neurosci. 1996; 16:3035-44.

194. Chen X, Grisham W, Arnold AP. X chromosome number causes sex differences in gene expression in adult mouse striatum. Eur J Neurosci. 2009;29:768-76.

195. Clarke TK, Ambrose-Lanci L, Ferraro TN, Berrettini WH, Kampman KM, Dackis CA, Pettinati HM, O'Brien CP, Oslin DW, Lohoff FW. Genetic association analyses of PDYN polymorphisms with heroin and cocaine addiction. Genes Brain Behav. 2012;11:415-23.

196. Yuferov V, Ji F, Nielsen DA, Levran O, Ho A, Morgello S, Shi R, Ott J, Kreek MJ. A functional haplotype implicated in vulnerability to develop cocaine dependence is associated with reduced PDYN expression in human brain. Neuropsychopharmacology. 2009;34:1185-97.

197. D'Addario C, Palazzo MC, Benatti B, Grancini B, Pucci M, Di Francesco A, Camuri G, Galimberti D, Fenoglio C, Scarpini E, Altamura AC, Maccarrone M, Dell'Osso B. Regulation of gene transcription in bipolar disorders: role of DNA methylation in the relationship between prodynorphin and brain derived neurotrophic factor. Prog Neuropsychopharmacol Biol Psychiatry. 2018;82:314-21.

198. Egervari G, Jutras-Aswad D, Landry J, Miller ML, Anderson SA, Michaelides M, Jacobs MM, Peter C, Yiannoulos G, Liu X, Hurd YL. A functional 3'UTR polymorphism (rs2235749) of prodynorphin alters microRNA-365 binding in ventral striatonigral neurons to influence novelty seeking and positive reward traits. Neuropsychopharmacology. 2016;41:2512-20.
199. Liang DY, Sun Y, Shi XY, Sahbaie P, Clark JD. Epigenetic regulation of spinal cord gene expression controls opioid-induced hyperalgesia. Mol Pain. 2014;10:59.

200. Liu QR, Lu L, Zhu XG, Gong JP, Shaham Y, Uhl GR. Rodent BDNF genes, novel promoters, novel splice variants, and regulation by cocaine. Brain Res. 2006; 1067:1-2.

201. Li X, Wolf ME. Multiple faces of BDNF in cocaine addiction. Behav Brain Res. 2015;279:240-54

202. Ghitza UE, Zhai H, Wu P, Airavaara M, Shaham Y, Lu L. Role of BDNF and GDNF in drug reward and relapse: a review. Neurosci Biobehav Rev. 2010;35:157-71.

203. Carvalho AL, Caldeira MV, Santos SD, Duarte CB. Role of the brain-derived neurotrophic factor at glutamatergic synapses. Brit J Pharmacol. 2008;153: S310-24.

204. Heberden C. Sex steroids and neurogenesis. Biochem Pharmacol. 2017;141: 56-62.

205. Karisetty BC, Joshi PC, Kumar A, Chakravarty S. Sex differences in the effect of chronic mild stress on mouse prefrontal cortical BDNF levels: a role of major ovarian hormones. Neuroscience. 2017;356:89-101.

206. Liu Y, Fowler CD, Young LJ, Yan Q, Insel TR, Wang Z. Expression and estrogen regulation of brain-derived neurotrophic factor gene and protein in the forebrain of female prairie voles. J Comp Neurol. 2001;433:499-514.

207. Miranda RC, Sohrabji F, Toran-Allerand CD. Presumptive estrogen target neurons express mRNAs for both the neurotrophins and neurotrophin receptors: a basis for potential developmental interactions of estrogen with the neurotrophins. Mol Cell Neurosci. 1993;4:510-25.

208. Klein LC, Corwin EJ. Seeing the unexpected: how sex differences in stress responses may provide a new perspective on the manifestation of psychiatric disorders. Curr Psychiatry Rep. 2002;4:441-8.

209. Luine VN, Beck KD, Bowman RE, Frankfurt M, Maclusky NJ. Chronic stress and neural function: accounting for sex and age. J Neuroendocrinol. 2007;19:743-51.

210. Bangasser DA, Curtis A, Reyes BA, Bethea $\Pi$, Parastatidis I, Ischiropoulos $H$, Van Bockstaele EJ, Valentino RJ. Sex differences in corticotropin-releasing factor receptor signaling and trafficking: potential role in female vulnerability to stressrelated psychopathology. Mol Psychiatry. 2010;15:877. 896-904

211. Riley AL, Hempel BJ, Clasen MM. Sex as a biological variable: drug use and abuse. Physiol Behav. 2018;187:79-96.

212. Thomas MB, Becker JB. Sex differences in prenatal stress effects on cocaine pursuit in rats. Physiol Behav. 2017 pii: S0031-9384(17)30358-X. https://doi.org/ 10.1016/j.physbeh.2017.10.019. [Epub ahead of print]. PMID: 29055747.

213. Anker JJ, Carroll ME. Reinstatement of cocaine seeking induced by drugs, cues, and stress in adolescent and adult rats. Psychopharmacology. 2010;208:211-22.

214. Lynch WJ. Modeling the development of drug addiction in male and female animals. Pharmacol Biochem Behav. 2018;164:50-61.

215. Beiter RM, Peterson AB, Abel J, Lynch WJ. Exercise during early, but not late abstinence, attenuates subsequent relapse vulnerability in a rat model. Transl Psychiatry. 2016;6:e792.

216. Puralewski R, Vasilakis G, Seney ML. Sex-related factors influence expression of mood-related genes in the basolateral amygdala differentially depending on age and stress exposure. Biol Sex Differ. 2016;7:50.

217. Kight KE, McCarthy MM. Using sex differences in the developing brain to identify nodes of influence for seizure susceptibility and epileptogenesis. Neurobiol Dis. 2014;72:136-43.

218. Uhl GR, Liu QR, Walther D, Hess J, Naiman D. Polysubstance abuse-vulnerability genes: genome scans for association, using 1,004 subjects and 1,494 singlenucleotide polymorphisms. Am J Hum Genet. 2001;69:1290-300.

219. Egan MF, Kojima M, Callicott JH, Goldberg TE, Kolachana BS, Bertolino A, Zaitsev E, Gold B, Goldman D, Dean M, Lu B, Weinberger DR. The BDNF val66met polymorphism affects activity-dependent secretion of BDNF and human memory and hippocampal function. Cell. 2003;112:257-69.

220. Cheng CY, Hong CJ, Yu YW, Chen TJ, Wu HC, Tsai SJ. Brain-derived neurotrophic factor (Val66Met) genetic polymorphism is associated with substance abuse in males. Brain Res Mol Brain Res. 2005;140:86-90.

221. Jiang $X, X u$ K, Hoberman J, Tian F, Marko AJ, Waheed JF, Harris CR, Marini AM, Enoch MA, Lipsky RH. BDNF variation and mood disorders: a novel functional promoter polymorphism and Val66Met are associated with anxiety but have opposing effects. Neuropsychopharmacology. 2005;30:1353-61.

222. Bath KG, Chuang J, Spencer-Segal JL, Amso D, Altemus M, McEwen BS, Lee FS. Variant brain-derived neurotrophic factor (Valine66Methionine) polymorphism contributes to developmental and estrous stage-specific expression of anxietylike behavior in female mice. Biol Psychiatry. 2012;72:499-504.

223. Becker JB, Perry AN, Westenbroek C. Sex differences in the neural mechanisms mediating addiction: a new synthesis and hypothesis. Biol Sex Differ. 2012;3:14.

224. Vassoler FM, White SL, Schmidt HD, Sadri-Vakili G, Pierce RC. Epigenetic inheritance of a cocaine-resistance phenotype. Nat Neurosci. 2013;16:42-7.

225. Barker DJ. The origins of the developmental origins theory. J Intern Med. 2007;261:412-7. 
226. McCarthy DM, Mueller KA, Cannon EN, Huizenga MN, Darnell SB, Bhide PG, Sadri-Vakili G. Prenatal cocaine exposure alters BDNF-TrkB signaling in the embryonic and adult brain. Dev Neurosci. 2016;38:365-74.

227. Tsai HW, Grant PA, Rissman EF. Sex differences in histone modifications in the neonatal mouse brain. Epigenetics. 2009;4:47-53.

228. Martinowich $K$, Hattori $D$, Wu H, Fouse $S$, He F, Hu $Y$, Fan $G$, Sun YE. DNA methylation-related chromatin remodeling in activity-dependent BDNF gene regulation. Science. 2003;302:890-3.

229. Chen WG, Chang Q, Lin $Y$, Meissner A, West AE, Griffith EC, Jaenisch R, Greenberg ME. Derepression of BDNF transcription involves calcium-dependent phosphorylation of MeCP2. Science. 2003;302:885-9.

230. Kurian JR, Forbes-Lorman RM, Auger AP. Sex difference in mecp2 expression during a critical period of rat brain development. Epigenetics. 2007;2:173-8.

231. Sohrabji F, Lewis DK. Estrogen-BDNF interactions: implications for neurodegenerative diseases. Front Neuroendocrinol. 2006;27:404-14.

232. Pfaff $D$, Keiner M. Atlas of estradiol-concentrating cells in the central nervous system of the female rat. J Comp Neurol. 1973;151:121-58.

233. Prewitt AK, Wilson ME. Changes in estrogen receptor-alpha mRNA in the mouse cortex during development. Brain Res. 2007;1134:62-9.

234. Greenfield SF, Trucco EM, McHugh RK, Lincoln M, Gallop RJ. The Women's Recovery Group Study: a Stage I trial of women-focused group therapy for substance use disorders versus mixed-gender group drug counseling. Drug Alcohol Depend. 2007;90:39-47.

235. McCarthy MM, Arnold AP. Reframing sexual differentiation of the brain. Nat Neurosci. 2011;14:677-83.

236. Conner JM, Lauterborn JC, Yan Q, Gall CM, Varon S. Distribution of brain-derived neurotrophic factor (BDNF) protein and mRNA in the normal adult rat CNS: evidence for anterograde axonal transport. J Neurosci. 1997;17:2295-313.
237. Luo AH, Tahsili-Fahadan P, Wise RA, Lupica CR, Aston-Jones G. Linking context with reward: a functional circuit from hippocampal $C A 3$ to ventral tegmental area. Science. 2011;333:353-7.

238. Shughrue PJ, Lane MV, Merchenthaler I. Comparative distribution of estrogen receptor-alpha and -beta mRNA in the rat central nervous system. J Comp Neurol. 1997;388:507-25.

239. Simerly RB, Swanson LW, Chang C, Muramatsu M. Distribution of androgen and estrogen receptor mRNA-containing cells in the rat brain: An in situ hybridization study. J Comp Neurol. 1990;294:76-95.

240. Xiao L, Becker JB. Quantitative microdialysis determination of extracellular striatal dopamine concentration in male and female rats: effects of estrous cycle and gonadectomy. Neurosci Lett. 1994;180:155-8.

241. Balkowiec A, Katz DM. Cellular mechanisms regulating activity-dependent release of native brain-derived neurotrophic factor from hippocampal neurons. J Neurosci. 2002;22:10399-407.

242. Hartmann M, Heumann R, Lessmann V. Synaptic secretion of BDNF after highfrequency stimulation of glutamatergic synapses. EMBO J. 2001;20:5887-97.

243. Sachidanandam R, Weissman D, Schmidt SC, Kakol JM, Stein LD, Marth G, Sherry S, Mullikin JC, Mortimore BJ, Willey DL, Hunt SE, Cole CG, Coggill PC, Rice CM, et al. A map of human genome sequence variation containing 1.42 million single nucleotide polymorphisms. Nature. 2001;409:928-33.

244. Feltenstein MW, See RE (2007). Plasma progesterone levels and cocaine-seeking in freely cycling female rats across the estrous cycle. Drug Alcohol Depend. 2007;89:183-9.

245. Doncheck EM, Urbanik LA, DeBaker MC, Barron LM, Liddiard GT, Tuscher JJ, Frick KM, Hillard CJ, Mantsch JR (2018). 17beta-estradiol potentiates the reinstatement of cocaine seeking in female rats: role of the prelimbic prefrontal cortex and cannabinoid type-1 receptors. Neuropsychopharmacology. 2018;43:781-90. 